Dear reader,

Please take into account the fact that there might be some discrepancies between this accepted manuscript and the final published version of the article.

Best,

The authors 


\title{
Old taphonomy issues, new charcoal data for Mesolithic contexts: Impact of fragment size and sampling context on the assemblages of Escabasses cave (SW France)
}

The corrections made in this section will be reviewed and approved by journal production editor.

Auréade Henry ${ }^{\mathrm{a}}$, Vanna Lisa Coli ${ }^{\mathrm{a}}$, Nicolas Valdeyron ${ }^{\mathrm{b}}$, Isabelle Théry-Parisot ${ }^{\mathrm{a}}$

aUniversité Côte d'Azur, CNRS-CEPAM, Nice, France

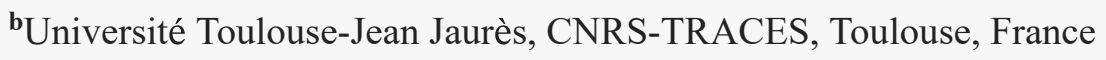

\begin{abstract}
Does fragment size influence significantly archaeological charcoal spectra? Does the floristic content of charcoal concentrations provide a representative image of the anthracological record? These taphonomy-related questions are as old as the first methodological groundwork in anthracology and therefore, they could be considered as solved. The aim of this paper is to show that they are still topical today, as depositional and post-depositional conditions vary between archaeological contexts, periods, and sites. With this in mind, we revisited the charcoal data of an Early Mesolithic occupation, level 6 of Escabasses cave, which had the particularity of yielding a significant amount of charcoal fragments over $4 \mathrm{~mm}$ size and numerous combustion features. This allowed to test the impact of different size classes (mainly $] 2-4[\mathrm{~mm}$ vs. $>4 \mathrm{~mm}$ ) and types of deposits (concentrated vs. scattered charcoal) on taxonomic diversity and proportions, as well as on the abundance of a key-taxon, deciduous oak (Quercus). Our results show that (i) contrarily to what is generally assumed, at Escabasses the proportions between taxa showed more variability according to size class than to types of deposit; (ii) size class deesid not impact floristic diversity; (iii) however, the probability to find higher Quercus frequencies within the $] 2-4[\mathrm{~mm}$ size class is significant. These results allude to different stages in the taphonomy history of the charcoals, potentially ranging from the type of occupation and related human practices to a specific postdepositional behavior of Quercus, suggested by previous studies.
\end{abstract}

\section{Introduction}


Taphonomical processes affecting archaeological charcoal occur at any stage from the initial acquisition of wood by past human groups until its final recovery and study in the laboratory by the archaeobotanist. Human selection, combustion, depositional and post-depositional agents are as many successive "filters" that can significantly alter our perception of past ligneous landscapes and human practices around firewood (ThéryParisot et al., 2010a). Hence, taphonomy studies in charcoal analysis or anthracology consist in identifying the effect of a given process occurring at a defined stage of the wood's- or the charcoal's- history and characterizing its impact on the recovered charred assemblages. In the same way as for other archaeological taphonomy studies, the impact of each filter - e.g., combustion, mechanical pressure, weathering - can be simulated in different ways through experimentation (see Théry-Parisot, 2001a; Chrzavzez, 2013; Chrzavzez et al., 2014). However, the specificity of charcoal taphonomy resides in the fact that there is mainly one single method to measure the effects of processes that are very different in nature: fragmentation studies. Thus, since the very early history of the discipline, the fragmentation process is at the heart of charcoal analysis and much is still to be learned about the way charcoal particles fragment in the archaeological record.

The methodological basis of anthracology (Chabal, 1982; 1991; Badal García and Heinz, 1991) was established on the basis of theoretical postulates backed up by practical work on numerous archaeological assemblages, while experimentation remained marginal (e.g., Bazile-Robert, 1982). This first impulse by the "Montpellier School" (Asouti and Austin, 2005: 1), led to the development of a strong methodological background, which allowed establishing the potential of charcoal analysis as a powerful paleoecological tool ( Chabal et al., 1999).

In this theory-building process, it is noticeable that fragmentation was already paramount in the questionings concerning assemblage representativeness: are charcoal assemblages more representative when the fragments are weighed or counted (e.g., Krauss-Marguet, 1980)? Do all size classes recovered during the excavation and sampling processes provide equivalent taxonomical information? By systematically constructing fragmentation histograms of archaeological charcoal assemblages from protohistorical and antique sites, Chabal $(1991,1997)$ observed a fragmentation pattern recurrent enough to be qualified as a "law" ("loi de fragmentation": Chabal, 1997: 45): the more abundant taxa are those yielding the largest fragments. In other terms, analyzing only large charcoal particles is equivalent to selecting the more frequent taxa, thus introducing a significant bias affecting species representativeness. Charcoal sieving and a quantitative approach of randomly selected fragments of all sizes within a given screening mesh were found to solve this issue (Chabal, 1997). Given that (i) no significant qualitative and quantitative differences were observed between charcoal samples composed of fragments over $5 \mathrm{~mm}$ and those over $2 \mathrm{~mm}$ and (ii) the smaller fragments are by definition more fragmented, inducing the necessity of analyzing a higher number of fragments to obtain a coherent image of the paleoflora, it was established that a wide screening mesh of 4$5 \mathrm{~mm}$ allows obtaining optimal results provided the material is abundant enough (Chabal, 1991, 1997). It is important to stress that by definition, fragments $>2 \mathrm{~mm}$ include the category $>5 \mathrm{~mm}$. Methodologically, this is justified by the fact that the choice of a screening mesh implies studying a sample composed of all kinds of fragments superior to the screen's aperture. Such an approach could also explain why the floristic results obtained for these two "paired" categories are comparable. However, it is to note that Badal-Garcia (1990), comparing the floristic results obtained by analyzing [2-5] $\mathrm{mm}$ vs. $\geq 5 \mathrm{~mm}$ charcoal fragments, arrived at similar conclusions regarding the Neolithic assemblages from Cova de Les Cendres (Spain). Methodologically, 
"splitting" what could be considered as one single size category ( $>2 \mathrm{~mm}$ ) into two classes, $2-5 \mathrm{~mm}$ and superior to $5 \mathrm{~mm}$, adds a level of detail as it becomes possible to compare the numerical contribution of the smaller fragments to the one of the larger ones $(>4-5 \mathrm{~mm}$ ), whose preservation in the charcoal assemblages is more hazardous.

Over the last decades, the increase of anthracology studies following at least partially the methodological steps of the Montpellier School has led to many successful paleoenvironmental and palethnographic reconstructions, as well as establishing methodological milestones (Pernaud, 1992; Fabre, 1996; Heinz and Thiébault, 1998; Ntinou, 2002). More recently, others have shown the distortion between assemblages resulting from flotation vs. handpicking, the latter leading to much poorer floristic assemblages in which the dominant taxon is usually overrepresented (see for instance, Vidal Matutano, 2016).

Current statistical analyses on experimental charcoal datasets created for taphonomy studies rely on size classes as independent variables (usually $] 1-2[\mathrm{~mm} ;] 2-4[\mathrm{~mm} ;>4 \mathrm{~mm}$ ) as they aim at investigating in-depth a final fragmentation state after submitting the material to one or several processes (e.g., Théry-Parisot et al., 2010b; Chrzavzez, 2013).

However, quite a long time has passed since anthracological publications have aimed at comparing quantitatively the information delivered by different size classes within one archaeological site or level and, to the best of our knowledge, there are no studies available for hunter-gatherer contexts. One explanation for this lack of methodological research were probably the compelling arguments made by Chabal and Badal in the late 80's and early 90's, with unquestionable results that seemed a priori applicable to all time periods.

It has also to be stressed that transposing their results to different, earlier chronological contexts can be problematic, as most prehistoric hunter-gatherer sites rarely yield large quantities of charcoal fragments over $4 \mathrm{~mm}$.

Escabasses cave in the Lot département (South-West France) is a notable exception to this rule with a great amount of "large" charcoal fragments $(>4 \mathrm{~mm})$ found in all the Mesolithic levels. Level 6 is particularly interesting, as in addition, it displays a high density of different types of combustion features. It is thus the perfect methodological setting for testing the validity of the anthracological postulates about fragmentation exposed above and particularly, their applicability to an Early Mesolithic context rich in charcoal - either scattered within the archaeological level or concentrated in hearths, clean-out deposits and other accumulations related to combustion activities. Hence, the aim of this paper is to pour new data into a quite older question: is there, after all, a bias in studying only one size class, even though all the methodological requirements for a paleoenvironmental analysis are fulfilled? And if so, which size class is it more coherent to consider?

\section{The study context}

Escabasses cave opens at 320 m a.s.l. on the karstic plateau (French: Causse) of Gramat, near the village of Thémines (Lot département, France - Fig. 1). Delimited to the South by the Lot and Célé valleys and to the North by the Dordogne valley, this low altitude plateau made of hard Jurassic limestone is remarkable by the 
high number of lapiaz, dolinas, and sinkholes. In this karstic context, the valleys running through the plateau are dry, while run-off contributes to a developed underground water network (Astruc and Coustou, 1993).

\section{Fig. 1}

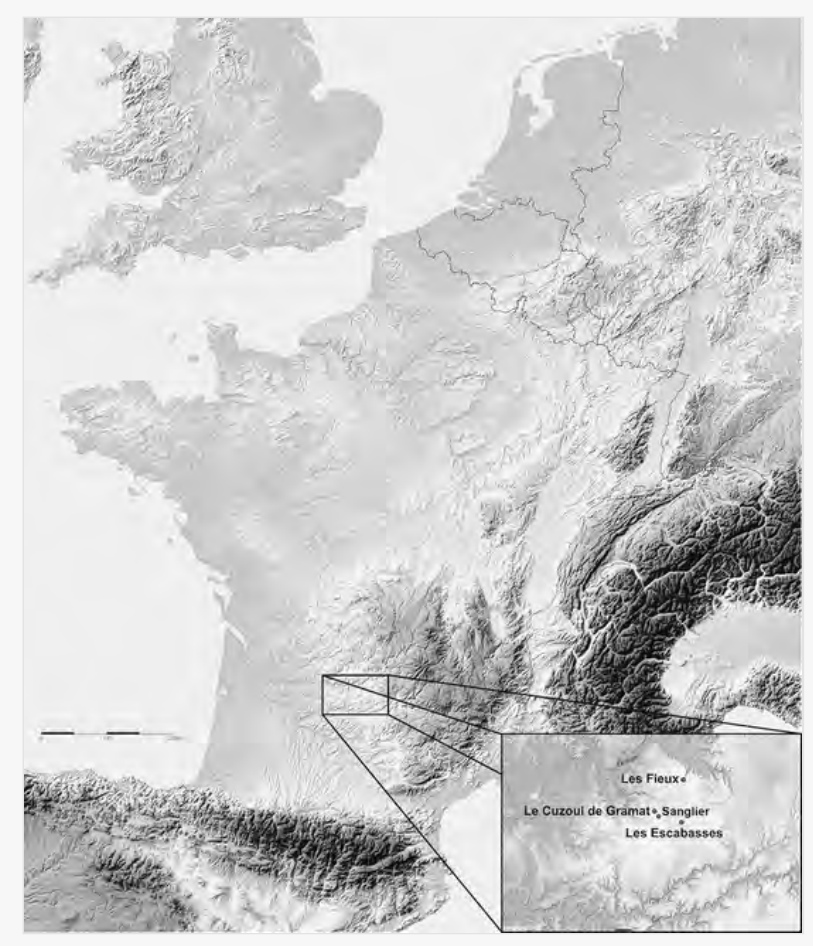

Location of the Gramat plateau with main sites yielding Early Mesolithic levels.

More subjected to erosion than the neighbouring Causses, the Gramat plateau has a more arid tonality with numerous exokarstic forms. Located near the south-western border of the Causse, Escabasses cave is surrounded by vegetation features typical of the area, supramediterranean white oak (Quercus pubescens) forest and its degradation stages. Associated species are Prunus mahaleb, Acer campestre, A. monspessulanum, Viburnum lantana, Cornus sanguinea, C. mas, Juniperus communis, Ligustrum vulgare, Prunus spinosa and Euonymus europaeus (authors' observations; Lavergne, 1963).

The cave opens at the SW bottom of a shallow sinkhole and is composed of five main segments within a total length of $330 \mathrm{~m}$. The entrance gallery, about $25 \mathrm{~m}$ deep, extends towards the outside by a small porch forming a shallow rockshelter, resulting from the collapse of blocks that constituted a much more developed porch ( Valdeyron et al., 1996).

After a brief passage of local excavators Lacam and Niederlender in the 1920s, Lorblanchet and Canet discover the first paintings attributed to the Upper Paleolithic in the early 1960's, which led them to undertake a series of surveys during the 1960's and 70's. One of their excavation trenches uncovered a relatively complete occupation sequence in the entrance gallery ranging from the Solutrean to the Antiquity. More recently, an excavation led by Valdeyron and collaborators between 1993 and 2002 allowed evidencing early Mesolithic levels very rich in archaeological features and remains, this being particularly true for level 6 ( 
Valdeyron, 2000; Valdeyron et al., 1995, 1996, 2004). As previously noted in other similar contexts of the area, due to visible anthropogenic and natural reworkings at play, the archaeological deposits consist in complicated imbrications of sedimentary units of different nature, limiting the possibility of individualizing occupation surfaces and thus, the pertinence of a spatial approach (Valdeyron et al., 1996). In addition to fine excavation methods, the only way to overcome this limitation was to adopt a stratigraphic approach, allowing to obtain coherent data in regard to the identity of these successive Mesolithic occupations. Indeed, the obtained radiocarbon dates are consistent with the material remains, according to which the Early as well as the Late Mesolithic are represented; level 6 and 5d are Montclusian (or "Middle" Sauveterrian) while the upper levels $5 \mathrm{c}$ to 5 are attributed to the Late Mesolithic (Fig. 2).

\section{Fig. 2}
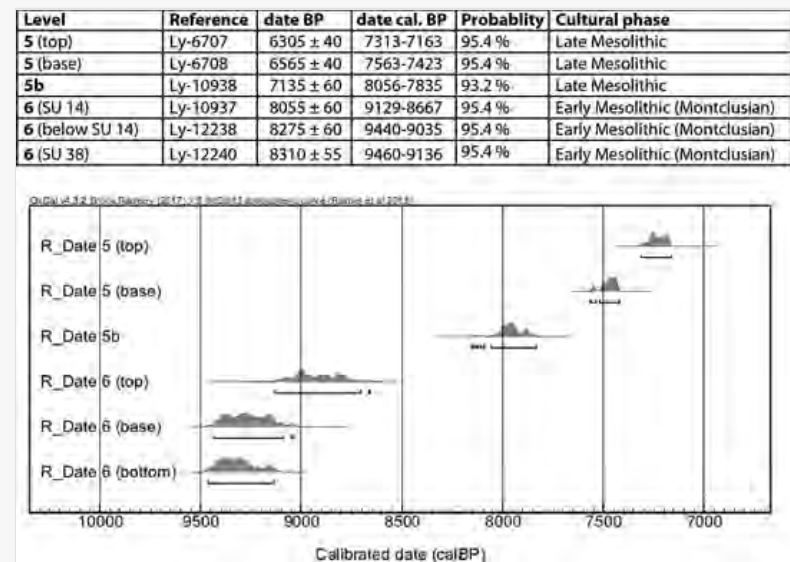

Conventional radiocarbon dates from Escabasses cave made on charcoal (taxa unidentified). Calibration made with the software OxCal v4.3.2, according to Reimer et al., 2013.

Given that the collapse of the porch disrupted different zones, the excavation of level 6 - and the subsequent charcoal sampling and study - was carefully delimited to a reduced area where the deposits were intact (Fig. 3 A). The sediment shows a quite light and fine-grained texture, contrasting with the underlying layer 7 mainly consisting of a massive orange clay deposit. On the contrary, level 6 bears all the markers of anthropization, with only a slightly clayish texture, and a light color due to the intense rubefaction of the sediment, and many charcoal inclusions that are more or less concentrated within the occupation area, also characterized by a variable density of snail (Cepaea nemoralis) shell fragments, very common in Early Mesolithic caves and shelters of the region (e.g., Barbaza et al., 1991). The combustion features (hereafter also labelled "SU", according to the excavation terminology, during which each feature received a unique Stratigraphic Unit number) are typologically variable, numerous and sometimes imbricated into one another, which did not always enable a clear individualization (Table 1; Fig. 3B). 


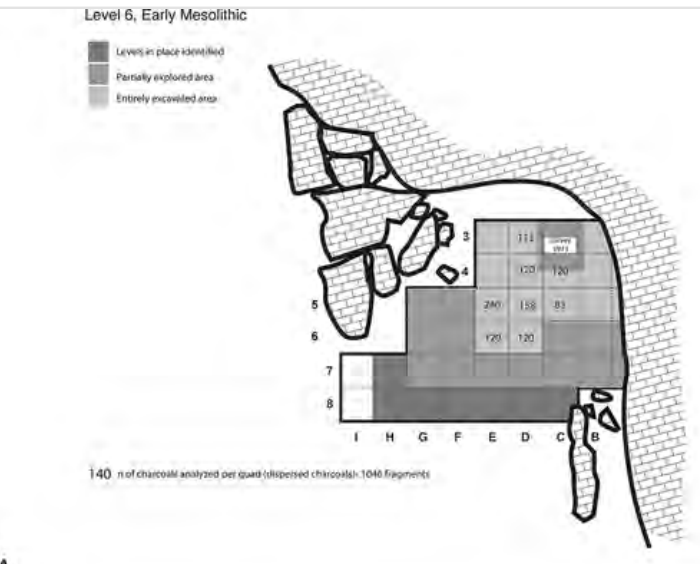

A.

B.

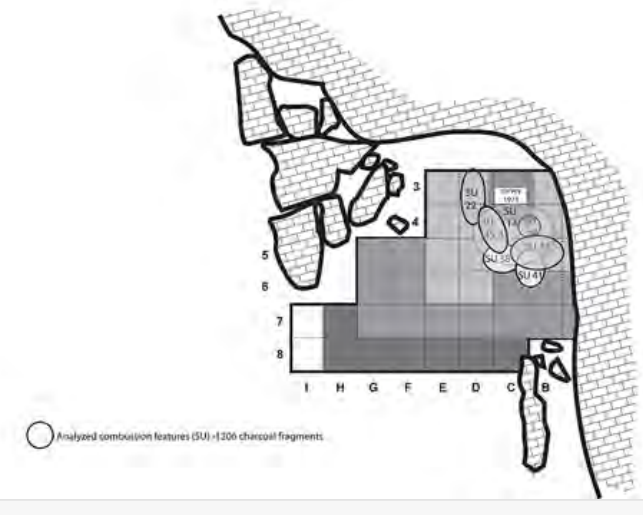

Map of the excavation with the location of the concentrated (A) and dispersed (B) charcoal samples.

Table 1

(i) The presentation of Tables and the formatting of text in the online proof do not match the final output, though the data is the same. To preview the actual presentation, view the Proof.

Combustion features sampled for charcoal analyses.

\begin{tabular}{|l|l|l|l|l|l|}
\hline Level & Quad & $\begin{array}{l}\text { SU } \\
\text { Nr. }\end{array}$ & $\begin{array}{l}\text { nr. frags. } \\
\text { analyzed }\end{array}$ & Type of feature & Observations \\
\hline 6 & C5, D5 & 26 & 100 & Large flat combustion structure & Cross-cuts SU 14 \\
\hline 6 & B3 & 20 & 100 & Small circular combustion structure & Rich in ashes \\
\hline 6 & B, C, D/4, 5 & 14 & 200 & Large oval shaped combustion & Numerous in situ heat-fractured \\
\hline 6 & $\begin{array}{l}\text { B4/5 and } \\
\text { C4/5 }\end{array}$ & 28 & 101 & Stone-filled combustion structure & Base of SU 14 \\
\hline 6 & D4 and D3 & 22 & 116 & Hearth refusal near SU 14 & Connected to SU $14 ?$ \\
\hline 6 & C5 & 36 & 100 & Combustion structure & Disrupted by Su 14 \\
\hline
\end{tabular}




\begin{tabular}{|c|c|c|c|c|c|}
\hline 6 & B5-C5 & 37 & 100 & Spread of white ashes & \\
\hline 6 & $\mathrm{C} 5$ & 38 & 101 & $\begin{array}{l}\text { Hollow stone-filled combustion } \\
\text { structure }\end{array}$ & Locally disrupted? \\
\hline $\begin{array}{l}6 \\
\text { base }\end{array}$ & $\mathrm{C} 5-\mathrm{C} 6$ & 40 & 32 & Stone-filled combustion structure & Not fully excavated \\
\hline $\begin{array}{l}6 \\
\text { base }\end{array}$ & $\mathrm{C} 5 / 6-\mathrm{B} 5 / 6$ & 41 & 118 & Pocket of rubefied sediment & Smear below SU 37 \\
\hline $\begin{array}{l}6 \\
\text { base }\end{array}$ & $\begin{array}{l}\text { C4-D4-C5- } \\
\text { D5 }\end{array}$ & 45 & 100 & Stone-filled combustion structure & \\
\hline $\begin{array}{l}6 \\
\text { base }\end{array}$ & $\mathrm{C} 4 / 5, \mathrm{D} 4 / 5$ & 43 & 11 & Oval-shaped ash deposit & Connected to SU 45 \\
\hline $\begin{array}{l}6 \\
\text { base }\end{array}$ & $\mathrm{C} 5$ & 42 & 27 & Ash layer below SU 41 & Undercuts the excavation trench \\
\hline
\end{tabular}

With a succession of levels dated from the Boreal and one level dated from the Early Atlantic period, the charcoal assemblage of Escabasses shows the progressive development from a pre-forest shrubland dominated by Rosaceae Prunoideae (levels 6 to 5b) to a deciduous, taxonomically more diverse, oak forest (level 5) close to the site (Fig. 4).

\section{Fig. 4}

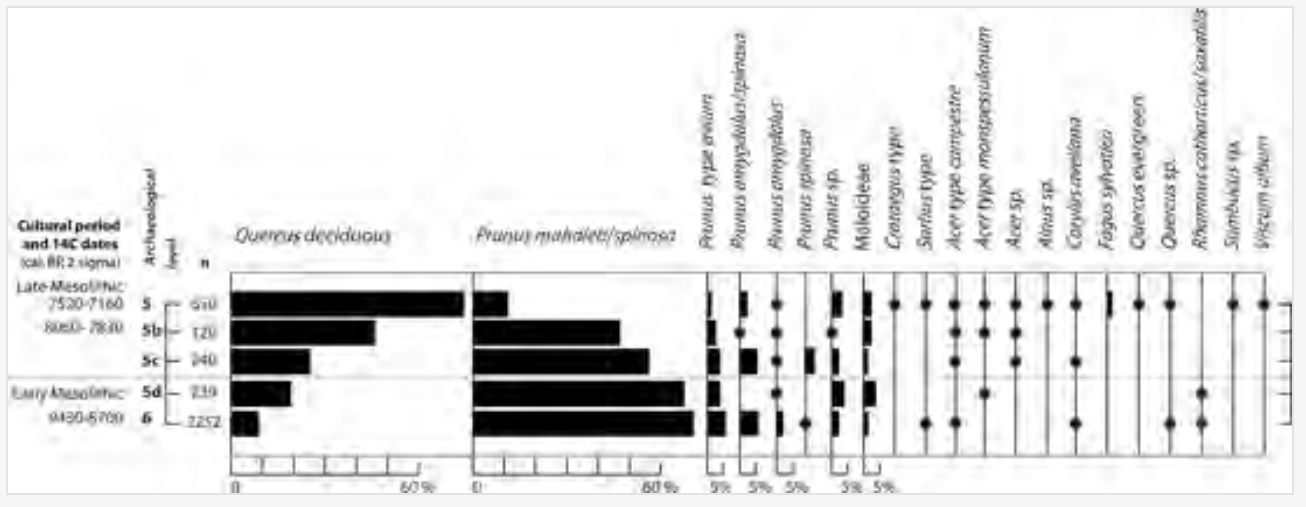

Anthracological diagram of Escabasses cave: Mesolithic levels.

The closing of the landscape in the course of the Mesolithic is also evidenced by zooarchaeology, with the faunal assemblage shifting gradually from a dominance of species living in open areas (aurochs and roe deer, level 6) to spectra with a majority of species typical of forested to closed forest environments such as wild boar and marten (Rivière, 2006).

A multivariate analysis applied to the charcoal assemblages of 25 archaeological levels from five sites (including Escabasses) evidenced that the vegetation dynamics around Escabasses cave are consistent with the 
records from other sites of the Gramat plateau (Henry et al., 2013): the first Early Mesolithic occupations are already characterized by a temperate vegetation cover (Fieux site, level D3, 11200-10258 cal. BP, see Henry et al., 2013). However, the specific geological, topographical and pedological context was probably responsible for a very contrasted development of the Holocene oak forest. At the scale of the Causse, the results reflect a mosaic of landscapes at different stages of openness, as some micro-regions show an early dominance of deciduous oak (Quercus fc.), whereas in other neighboring sites such as Escabasses or Sanglier, the evolution towards an oak forest remains long blocked at the stage of pre-forest Prunetalia, probably due to local xeric conditions and poor soil development (Henry et al., 2013).

\section{Dataset and methods}

\subsection{Preliminary dataset analyses}

For this study, we extracted information regarding sample type (dispersed-quad or scattered-feature) and fragment size ( $>4 \mathrm{~mm}$ or $] 2-4[\mathrm{~mm}$ ) from the charcoal assemblage of level 6 (Table 2), as this information was already available in the database built for the paleoecological analysis (Henry, 2011).

\section{Table 2}

(i) The presentation of Tables and the formatting of text in the online proof do not match the final output, though the data is the same. To preview the actual presentation, view the Proof.

Escabasses level 6: floristic results per categories taken into account. For detailed results per quad/feature, see Supplementary Material 1.

\begin{tabular}{|c|c|c|c|c|c|c|c|c|}
\hline \multirow{2}{*}{$\begin{array}{l}\text { Charcoal deposit } \\
\text { Taxa Level 6//Fragment size }\end{array}$} & \multicolumn{3}{|c|}{ Concentrated } & \multicolumn{4}{|l|}{ Scattered } & \multirow{2}{*}{ GRAND TOTAL } \\
\hline & {$[2-4] \mathrm{mm}$} & $>4 \mathrm{~mm}$ & Total & {$[2-4] \mathrm{mm}$} & $>4 \mathrm{~mm}$ & No data & Total & \\
\hline Acer type campestre & 3 & & 3 & & & & & 3 \\
\hline Corylus avellana & 3 & 2 & 5 & & & & & 5 \\
\hline Maloideae & 9 & 2 & 11 & 5 & 12 & 4 & 21 & 32 \\
\hline Sorbus type & 2 & & 2 & & & & & 2 \\
\hline Prunus avium/cerasus & 24 & 42 & 66 & 31 & 28 & & 59 & 125 \\
\hline Prunus mahaleb/spinosa & 373 & 499 & 872 & 226 & 409 & 92 & 727 & 1599 \\
\hline Prunus amygdalus/spinosa & 22 & 24 & 46 & 23 & 22 & 3 & 48 & 94 \\
\hline Prunus amygdalus & 3 & 12 & 15 & 9 & 17 & & 26 & 41 \\
\hline Prunus spinosa & 4 & 3 & 7 & & 2 & 6 & 8 & 15 \\
\hline Prunus sp. & 13 & 9 & 22 & 16 & 9 & 1 & 26 & 48 \\
\hline
\end{tabular}




\begin{tabular}{|l|l|l|l|l|l|l|l|l|}
\hline Quercus deciduous & 94 & 40 & $\mathbf{1 3 4}$ & 65 & 39 & 7 & $\mathbf{1 1 1}$ & $\mathbf{2 4 5}$ \\
\hline $\begin{array}{l}\text { Quercus sp. } \\
\text { Rhamnus catharticus/saxatilis }\end{array}$ & 1 & 4 & $\mathbf{4}$ & & 1 & 1 & 3 & $\mathbf{2}$ \\
\hline Unidentifiable & 8 & 10 & $\mathbf{1 8}$ & 4 & 6 & $\mathbf{3}$ & $\mathbf{8}$ \\
\hline Total & 559 & 647 & $\mathbf{1 2 0 6}$ & 380 & 546 & 120 & $\mathbf{1 0 4 6}$ & $\mathbf{2 2 5 2}$ \\
\hline
\end{tabular}

It is to note that the total number of charcoals identified for the two categories "concentrated" and "dispersed", respectively 1206 and 1046, exceeds by far the methodological requirements for an optimal statistic representativeness, evaluated between 250 and 500 fragments per archaeological level depending on the taxonomic richness of the assemblages (Chabal, 1997).

With 13 taxa, the floristic diversity of level 6 is average when compared to equivalent chrono-cultural contexts (Delhon and Thiébault, 2009; Henry, 2011). The main characteristic of the samples from Level 6 are their great homogeneity i.e., no evident rupture is perceptible in the floristic content at a spatial level (e.g., between quads), but also between the spectra resulting from the study of concentrated vs. dispersed charcoal samples. This is confirmed by preparatory Factor (FA) and Hierarchical Clustering (HCA) analyses (for detailed results, see Supplementary Material 2). These indicate that noticeable variability factors impact only 4 from 18 samples and concern (i) the contributions of "rare" taxa (i.e., appearing sporadically and in extremely low frequencies) and (ii) the fluctuations in the frequencies of secondary taxa (ubiquitous and recurrent contributors to the floristic list, basically Quercus and Prunus type avium). There are no outstanding abnormalities in the anthracological sense of the term, as the hierarchy between taxa is equivalent within each quad and SU, characterized by the very strong dominance of Prunoideae and the secondary importance of deciduous oak, the two taxa with the highest numerical weight. Within this general picture, SUs seem to contribute more to the global floristic variability than quads, mainly from a qualitative point of view.

Nevertheless, the global percentages of Prunoideae and Quercus obtained for the charcoal fragments dispersed within the quads appear to yield no differences with those of the SUs (Fig. 5A). However, when reallocated by size class $(>4 \mathrm{~mm}$ or $] 2-4[\mathrm{~mm})$, it seems that Prunus is better represented within the $>4 \mathrm{~mm}$ class at the expense of Quercus (Fig. 5B).

\section{Fig. 5}



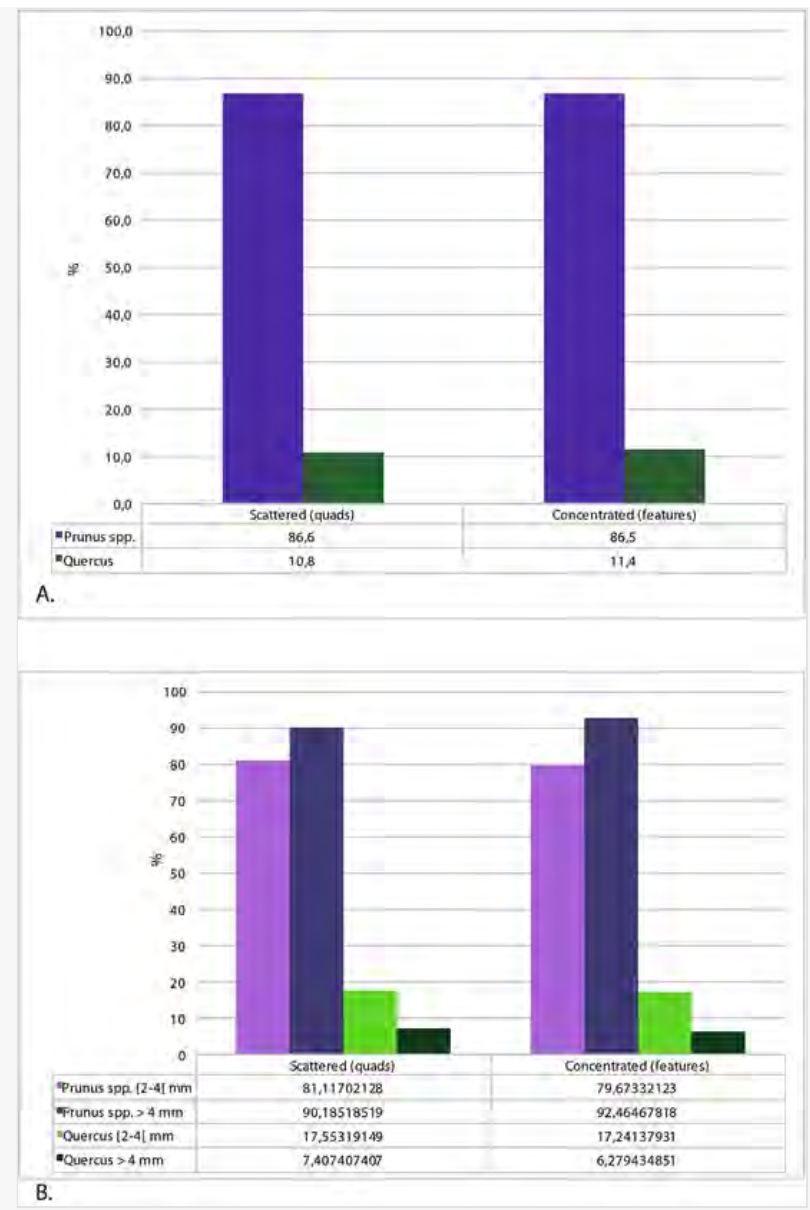

A. Proportions of Prunus spp. and Quercus according to sampling context (dispersed/concentrated). B. Proportions of Prunus spp. and Quercus according to fragment size and sampling context.

A set of chi-square tests performed on the raw Prunus and Quercus values (rows) per sampling context or size class (columns) confirm this first observation (see Supplementary Material 3 for data and detailed results). While the influence of the sampling context (quad vs. SU) on the frequencies of Prunus and/or Quercus is not significant at the alpha significance level of 0.025 , the size class, on the contrary, appears to have a significant effect. This is true whether the considered size classes are $>4 \mathrm{~mm}$ vs. $] 2-4[\mathrm{~mm}$, on which we ran a chi-square test, or $>4 \mathrm{~mm}$ vs. $>2 \mathrm{~mm}$, on which we ran a McNemar test (adapted for paired samples). In sum, the choice of studying only smaller or larger fragments may have an impact upon the frequencies of major taxa, which would in this case study particularly affect Quercus values.

\subsection{Statistical questions and tools}

These two preliminary sets of tests (multivariate analysis FA/HCA and contingency table analyses chisquare/Fisher/Pearson's residuals) allow us to better understand the structure of our data and to formulate the following research questions:

- Considering the slightly higher floristic variability within the SUs: to what extent does the sampling context have a statistically significant impact on floristic diversity? Could fragment size also be a variable affecting floristic diversity? 
- In regard of the impact of size class on the global co-variations of Prunus and especially, Quercus frequencies, to what extent does the range of Quercus values obtained between samples of different size classes differ from the inter-Quad or inter-SU variability (inherent to all charcoal studies)?

If the observed variations result less from sample variability than from the study of different size classes, we can conclude to the existence of a representativeness issue due to a methodological bias. In this specific research context, where deciduous oak plays a key-role in post-Glacial vegetation dynamics, the question of the over- or underrepresentation of Quercus is particularly important.

The fact that there are less than 30 features and quads induced the use of non-parametric tests. First, a Spearman correlation test, which favors non-linear, monotonous relations, is used to investigate the degree of correlation between number of analyzed charcoal fragments and number of taxa for each sample and size category. The Mann-Whitney and Kruskal-Wallis/Multiple comparisons tests are used here to highlight the differences between sample types (Quad - SU) and fragment size (>4 mm- $2-4[\mathrm{~mm})$ in what regards (i) the number of identified taxa and (ii) the abundance of oak. All tests were performed with the software Excel Stat. Box plots were created with MATLAB Release $2018 \mathrm{~b}$.

\section{Does size matter more than context?}

\subsection{The number of identified taxa is a function of the number of observed fragments}

Does the number of identified taxa vary significantly according to fragment size or sample type? In order to answer this question, we have to acknowledge the fact that this number depends to a certain extent of the total number of analyzed fragments.

Indeed, at a 0.025 alpha significance level, the Spearman test shows a positive correspondence between the number of identified taxa and the number of analyzed fragments (correlation coefficient Rhô 0.660; p-value 0.00150). When the samples are split according to fragment size or sample type, this correlation remains positive and almost always significant at the chosen significance level (see Fig. 6A-C; Supplementary Material 4). 

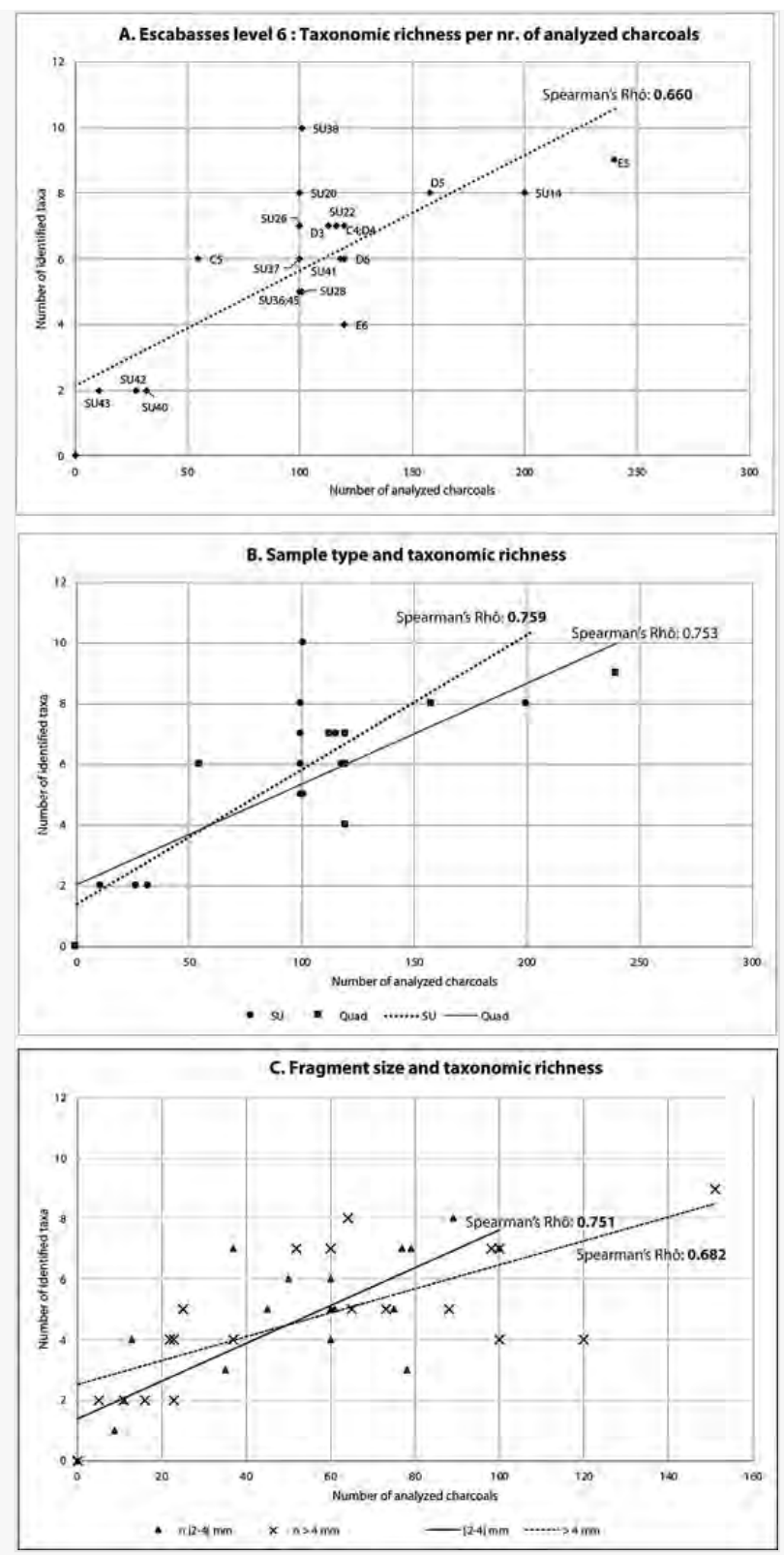

Correlations between number of analyzed fragments and number of identified taxa. A. Total samples B. Concentrated (SU) vs. dispersed (Quad) charcoal samples. C. Small ( $] 2-4[\mathrm{~mm})$ vs. large ( $>4 \mathrm{~mm})$ size class. Rhô values in bold are statistically significant at an alpha significance level of $0_{\underline{\underline{*}}-2} 025$.

We thus considered that the very low floristic diversity (1-2 taxa) observed within some samples was only imputable to the low number of analysed fragments (always less than 30). Thus, in order not to bias the distribution of the values, the poorest individuals (samples) where not taken into account in the following calculations.

\subsection{Impact of size class and sample type on the number of identified taxa}

With $50 \%$ of the samples yielding between 4 and 7 taxa and medians respectively ranging from 5 to 6.5 taxa, the floristic diversity appears comparable between quads, SUs or size fractions (Fig. 7A). 

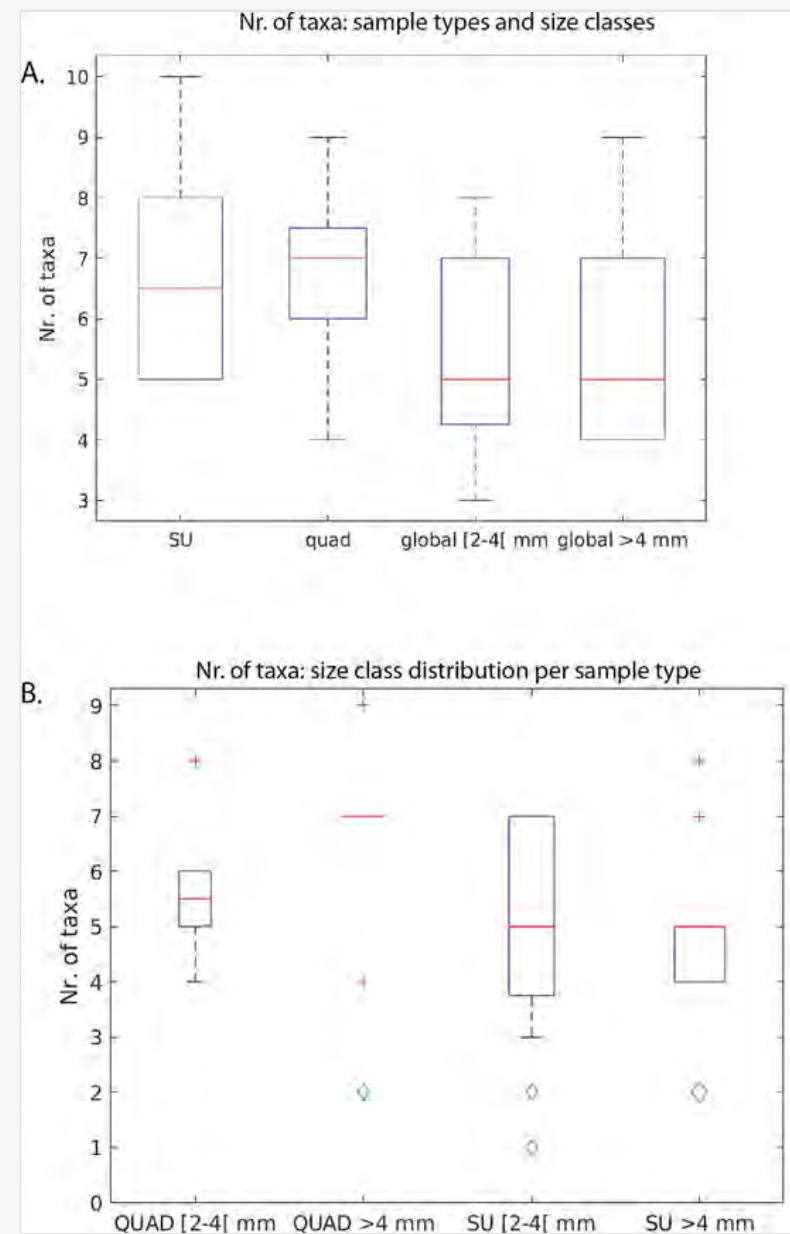

A. Nr. of taxa: scattered (quad) vs. concentrated (SU) charcoal. B. Nr. of taxa and size classes according to type of charcoal deposit - Samples with less than 2 identified taxa and less than 30 studied fragments are indicated with green diamonds but were not taken into account in the calculations. The width of the box plots is proportional to the number of studied fragments. (For interpretation of the references to color in this figure legend, the reader is referred to the web version of this article.)

Nevertheless, the values of the quads seem to be characterized by a lesser variability and a somewhat higher floristic diversity. This appears even more clearly when the fragments from the quads and SUs are classified according to size (Fig. 7B); quads appear somewhat richer than SUs, while $>4 \mathrm{~mm}$ charcoal provides more homogeneous values than the $] 2-4[\mathrm{~mm}$ size class. In order to assess if these observations are statistically significant, we ran a pair of Mann-Whitney tests on the values displayed in Fig. 7A and a Kruskal-Wallis test on those from Fig. 7B (Supplementary material 5). For both test sets (Mann-Whitney p-values: 0.844; 0.756; Kruskal-Wallis approximated p-value: 0.242 ), the results show that at the alpha significance level of 0.025 , the H0 hypothesis cannot be rejected i.e., that no significant difference was detected in the distributions of the values (number of taxa) characterizing the variables (different types of samples, split or not according to size classes). Thus, at Escabasses, size fraction, but also sample type, appear to have only a limited impact on the number of identified taxa.

\subsection{Size of charcoal fragments and proportions of a key-taxon: Deciduous Quercus}


As it is the case with the number of identified taxa, the distributions of deciduous oak percentages of scattered vs. concentrated charcoal samples yield very close medians around 8-10\%. More interestingly, when considering only the size classes, the variability of oak percentages appears higher, with medians between 6 and $13 \%$, the lowest values corresponding to the $>4 \mathrm{~mm}$ group (Fig. 8A). This pattern is even more accentuated when dividing the fragments belonging to the two sample types into their respective size categories, clearly separating the $] 2-4[\mathrm{~mm}$ from the $>4 \mathrm{~mm}$ groups (Fig. $8 \mathrm{~B}$ ). Within the first group the medians are of about $12-13 \%$, while those of the second are much lower, around 5\%.

\section{Fig. 8}

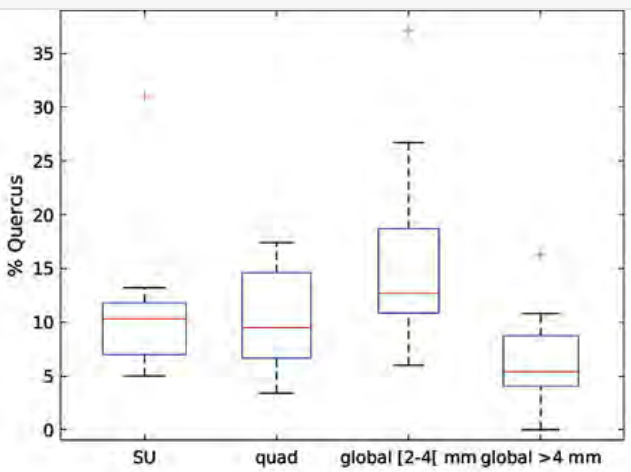

A.

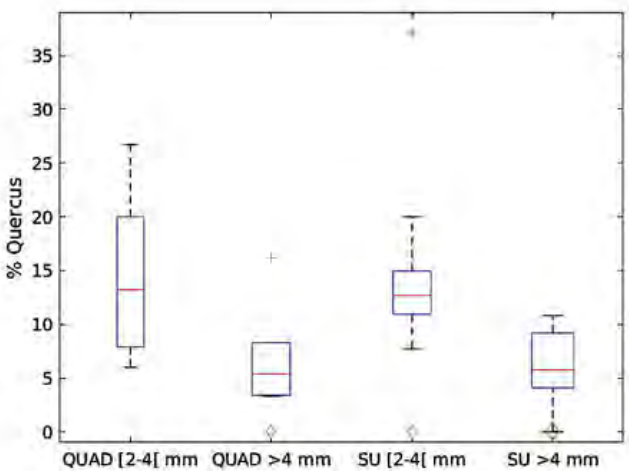

B.

Quercus percentages per sample. A. Comparison between scattered (quad) and concentrated charcoal deposits (SU). B. Comparison between fragment size classes per SU and quadSamples with less than 25 studied fragments are indicated with green diamonds but were not taken into account in the calculations. The width of the boxes is proportional to the number of studied fragments. (For interpretation of the references to color in this figure legend, the reader is referred to the web version of this article.)

In order to understand if, contrarily to the floristic richness, the variations of Quercus are significant, we ran another pair of Mann-Whitney tests on the Quercus frequencies, previously transformed into ordinal values. In order to obtain these, we favored a qualitative assessment taking into account the pertinence of these variations from an anthracological viewpoint over the use of an automatic computerized transmutation (see Supplementary Material 6). Our oak percentages (0-37\%) were thus reallocated into 5 classes ranking from 0 (absent) to 4 (abundant). 
The Mann-Whitney test detects no difference in the distributions of oak values within the dispersed (Quads) vs. the concentrated (SU) charcoal samples at the alpha significance level 0.025 (p-value: 0.817$)$. Thus, the H0 hypothesis has to be adopted i.e., there is no difference in the ranges of oak values obtained through the study of dispersed vs. concentrated charcoal. On the contrary, at the same significance level, the Mann-Whitney test indicates a significant difference in the distributions of oak values within the smaller size class vs. those of the $>4 \mathrm{~mm}$ one (p-value: $<0.0001)$. The alternative hypothesis Ha has to be adopted: the distribution of oak values obtained through the study of $] 2-4[\mathrm{~mm}$ vs. $>4 \mathrm{~mm}$ size class fragments is significantly different. The Kruskal-Wallis test performed on the individuals allocated to their respective sample types and fragment sizes also indicates that the $\mathrm{H} 0$ hypothesis must be rejected i.e., there is a significant difference in the distributions of at least one pair of samples (oak frequencies) at the significance level 0.025 (p-value 0.021). The results of the multiple pairwise comparisons (Dunn's procedure) propose a classification of the samples within two groups; the first one, A, is composed by the quads and the SUs composed of $] 2-4[\mathrm{~mm}$ size class fragments. The second one, B, is composed by the quads and the SUs with $>4 \mathrm{~mm}$ charcoal fragments. However, it is to note that the sample "Quads $>4 \mathrm{~mm}$ " belongs to both groups A and B. This being said, the differences between the latter and group A are markedly more pronounced than with the other sample from group B. In any case, and despite the weak potency of this test in regard of the low effectives, some differences remain significant whereas they are systematically more pronounced within size classes than sampling contexts.

Do these results highlight i) the differential preservation of Quercus in the archaeological record or ii) an overrepresentation within the $>4 \mathrm{~mm}$ size class of the more frequent taxonomic group constituted by Prunoideae and dominated by Prunus mahaleb/spinosa?

\section{Discussion}

\subsection{An underrepresentation of Quercus within the larger size class?}

The question of a specific taphonomic behavior of oak is legitimate, as several experimental studies point out its differential preservation in comparison to other taxa. First of all, during the combustion, deciduous oak produces more ashes than other taxa and comparatively less charcoal (Théry-Parisot et al., 2010b). Compression experiments on 302 charcoal fragments from 10 taxa showed that deciduous Quercus charcoal had the lowest mechanical resistance (crushing strength). The most probable explanation for the low resistance of a charcoal fragment originating from a very dense wood such as deciduous oak is its anatomy, namely the existence of two types of weakness planes, one transversal created by the porous early wood zone and one tangential corresponding to the very wide aggregated rays (Chrzavzez et al., 2014). As a result of this overfragmentation, Quercus was the only taxon that was significantly overrepresented in the $>4 \mathrm{~mm}$ size class (Ibid.) Within the variety of experiments (trampling, weathering or imbibition-desiccation and freeze-thaw cycles) performed on charcoal samples by Chrzavzez (2013), Quercus showed the most deviant behavior, as this taxon, and especially Q. pubescens, was either over- or under-fragmented. The factors of this variability were mostly unclear and seemed to be imputable to intra-specific variability factors, but were also possibly linked to initial fragment size, as the Quercus fragments used in the experiments tended to be slightly smaller than those from other taxa. Indeed, a relationship was observed between fragmentation intensity and initial charcoal size, suggesting that larger fragments tend to fragment more (Chrzavzez, 2013). To summarize, even 
though higher fragmentation can lead to an overrepresentation of Quercus, it could also make this taxon disappear faster from the larger size classes, re-fragmenting it into the smaller categories, especially if it produces relatively less charcoal than other taxa to begin with.

However, these experimental observations remain difficult to transpose to archaeological situations, as many variability factors remain unexplored experimentally and as the conditions of assemblage formation and taphonomy vary between deposits and sites (Chrzavzez, 2013). In the state of current research, even though it may seem that Quercus has a specific behavior, this argument is not verifiable at Escabasses, as this behavior is not constant throughout the anthracological sequence. Indeed, the simplified charcoal diagram of Escabasses including the results according to size class for all the Mesolithic levels (Fig. 9) shows that in level 5, in which Quercus becomes dominant, its proportions are higher in the $>4 \mathrm{~mm}$ than in the $] 2-4[\mathrm{~mm}$ size class.

\section{Fig. 9}

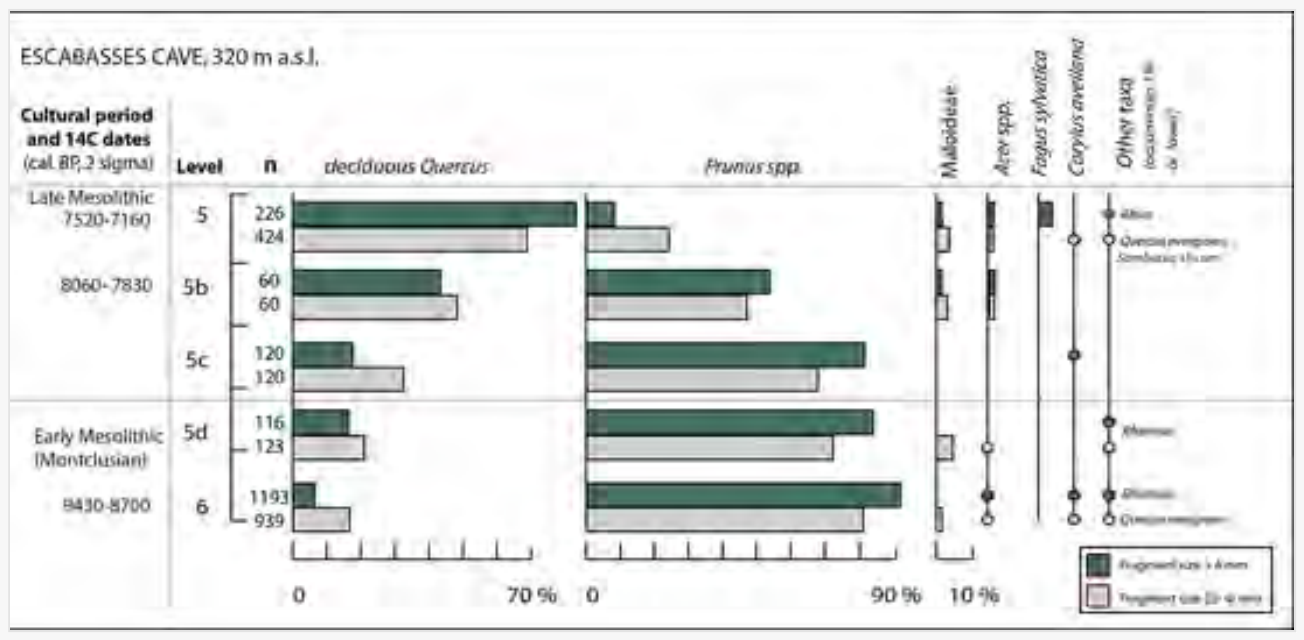

Simplified charcoal diagram of Escabasses site with numerical contribution of each size class.

Thus, Quercus is "underrepresented" within the larger size class as long as it is of secondary importance. Hence, the only observation that seems valid is the overrepresentation of the most frequent taxon within the $>4 \mathrm{~mm}$ size class. In sum, the total range of variation between size classes observed for the Mesolithic sequence within the two co-dependent taxonomic groups Prunoideae and deciduous Quercus is consistently of $8-15 \%$. The taxon showing the highest percentages in the $>4 \mathrm{~mm}$ size class appears to be the dominant one.

Hence, there might be a distortion at play between the quantitative results delivered by different size classes even when all studied fragments were recovered by systematic screening and randomly selected for the study. Does this mean that the study of one size class at the expense of others should be preconized?

\subsection{If size does matter, then which one choose?}

Basically, and summarizing Chrzavzez's (2013) observations, the distortions linked to overfragmentation hazards are more limited within the $>4 \mathrm{~mm}$ than within the $] 2-4[\mathrm{~mm}$ size class, whereas they are even more pronounced within the [1-2 mm] class. However, the risk for the more frequent taxon to be overrepresented is 
higher for the $>4 \mathrm{~mm}$ class. Thus, there are pros and cons for the study of each size class, as suggested by the results of this study: the $4 \mathrm{~mm}$ size class yields a satisfying floristic diversity, which seems to be obtained with a lesser number of fragments compared to the lower size class, reducing effort and over_fragmentation hazards. The latter are well perceptible in the $] 2-4[\mathrm{~mm}$ size classes as there is more variability in taxa frequencies between the samples, even though fragmentation may not be the only factor responsible. Within this size class, overrepresentation of the most frequent taxa may be more limited, even though as Chrzavzez (2013) underlines, this may not always be the case. In this regard, it is safe to declare that both of these size classes are complementary and thus, interesting to keep for the study, while their comparison enables methodological reflections. Indeed, the differences between the two size classes considered here confirm that each class follows a consistent pattern interpretable in terms of vegetation dynamics (e.g., Chabal, 1997), with the continuous development of deciduous oak; on the contrary, considering alternately one or the other size class may lead to more significant, sometimes even inexplicable, variations in anthracological content. For instance, studying the $] 2-4[\mathrm{~mm}$ size class for level 6 and then focusing on the $>4 \mathrm{~mm}$ fraction for levels $5 \mathrm{~d}$ and $5 \mathrm{~b}$ would lead to conclude that the dynamic of deciduous oak is stationary in the first three occupation levels. This variability linked to differences in the considered size classes might be even a parameter to consider when comparing sites that are temporally and spatially very close. For instance, the Mesolithic charcoal spectra from Sanglier cave (Théry-Parisot, 2001b), also largely dominated by Prunoideae, result from the exclusive study of charcoal over $4 \mathrm{~mm}$; one can assume that they might be slightly overrepresented at this site at the expense of deciduous oak. If considering different size classes is methodologically enriching, it should not be considered a methodological condition to obtain a representative charcoal assemblage (e.g., Smart and Hoffmann, 1988). Even though no universal guidelines emerge from this study, some conclusions are applicable to other contexts:

(i) as there are pros and cons for the study of each size class, it is legitimate to work only with one size class provided the material is abundant enough and the other methodological requirements are fulfilled; however, it is indispensable to provide indications about the size class studied and to be consistent in the choice of this size class;

(ii) indeed, randomly selecting a variety of fragments of different sizes may induce a supplementary risk factor directly linked to the variable abundance of each size class between sampling contexts;

(iii) given their limitations in terms of effort-yield and fragmentation hazards, the smaller size classes ([1-2 mm] and lower) should be studied only when the upper size classes are not available;

(iv) categorization into size classes (and thus, considering more than one class) helps better understanding the assemblages and enables more accurate comparisons between sites, levels or experimental series.

\subsection{When size matters more than context}

The implications of these conclusions are especially relevant, as many current charcoal studies do not provide clear indications of size, while following early observations, the sampling context (dispersed or concentrated) 
is always specified, as it is still regarded as a potential bias affecting paleoecological representativeness. Indeed, several authors noticed that concentrated charcoal remains were often improper for paleoecological reconstructions as their taxonomic diversity was impoverished and the proportions between taxa abnormal compared to the floristic information delivered by the dispersed charcoal (e.g. Heinz, 1988; Chabal, 1991; Pernaud, 1992). This was attributed to the short time of formation of this kind of deposits, reflecting only too limited episodes of wood acquisition and use for them to be representative of the surrounding vegetation. Pernaud (1992) showed that concentrated deposits provide coherent paleoenvironmental reconstructions under specific conditions. Our study shows that in some instances, differences are more pronounced between size classes than between concentrated vs. dispersed charcoal. But again, Mesolithic hunter-gatherer contexts were not considered in these early works, which indicates that is it important to take into account the specificities of each chrono-cultural context or even, each site, in order to adapt methodologically with each new occasion, as it has been suggested for other hunter-gatherer (Paleolithic) contexts (Théry-Parisot, 2002; Théry-Parisot et al., 2018).

The fact that the cumulated values of, on the one hand, feature contents and, on the other, dispersed charcoal samples are so close could provide clues of palethnological nature regarding the regional Mesolithic. A first observation about several sites studied in the area would be that the content of individual hearths is rarely floristically poor or abnormal (Henry et al., 2013; Henry and Boboeuf, 2016). Within the sites showing a real accumulation of combustion features, such as Escabasses level 6 or Fieux Level D1, there is a real concordance between the cumulated charcoal contents of the features and those of the layers (Henry, 2011). This could be a typical feature of specific site types interpreted functionally as repeated, short-term occupations (logistical or residential) by small groups (e.g., Valdeyron et al., 2011; Henry and Boboeuf, op. cit.). In this case, and in the absence of extensive cleaning activities and highly variable wood acquisition behavior, the dispersed charcoal would just correspond to a quasi direct function of the cumulated content of the hearths. Its paleoecological representativeness would thus more be based on the fact that the hearth contents are successions of similar wood gathering episodes over several decades or even centuries, than on an accumulation of "real" living floors resulting from long-term occupations necessitating a more extended wood acquisition area, resulting in a diversified floristic spectrum, really distinguishable from a punctual burning event containing a very limited number of taxa. In the absence of micromorphological and other specialized analyses regarding the formation and functioning of burning features at Escabasses, it seems difficult to further hypothesize about this question, but it is definitely a lead to follow in order to further unravel Mesolithic behavior(s).

\section{Conclusion}

As in other domains of pyrotechnology (see Aldeias, 2017), experimental standards and procedures for the study of archaeological wood charcoal have increased significantly over the last two decades, playing a decisive role in shaping anthracology and charcoal taphonomy studies as they are today (Théry-Parisot, 2001; Chrzavzez et al., 2014; Théry-Parisot et al., 2010b, 2016; Théry-Parisot and Henry, 2012; Henry and ThéryParisot, 2014; Lancelotti et al., 2010). These standardized experiments, in which the material is submitted to one or several in vivo and/or in vitro processes (see Chrzavzez, 2013), have allowed us to gain significant knowledge about the differential preservation of taxa towards the combustion process and different post- 
depositional factors such as trampling, weathering or imbibition-desiccation and freeze-thaw cycles (ThéryParisot, 2001a; Chrzavzez, 2013; Dussol et al., 2017). As their aim is to identify relationships between a process and its effect on charcoal, the final goal of these studies is to propose "corrective" solutions leading to more accurate interpretations of archaeological charcoal diagrams in terms of paleoecology or human behavior. As we advance in this direction with more experimental studies, going back to the archaeological material without loosing sight of the wider picture is paramount, from the characteristics of the charcoal assemblage itself, to the contributions of other taphonomy studies such as the ones geoarcheology, micromorphology or zooarcheology can provide. In this paper, we showed that the early questions about charcoal deposition and fragmentation are still valid and furthermore, that they should be addressed for each archaeological context and confronted to pertinent experimental data whenever possible. We believe that eventually, taking into account the highest number of parameters, including fragmentation, and linking them to the existing experimental databases, may help understand recurrent processes that could be related to specific filters such as human behavior and in this sense, shed light on past fire-related practices.

\section{Author statement}

This article was conceptualized and written by Dr. Henry. Dr. Coli contributed to the formal analysis of the data. Drs. Théry-Parisot and Valdeyron, involved in the initial Ph. D. project from which this paper is derived from, proofread and validated the final version of the manuscript. Two anonymous reviewers contributed to improving the manuscript. The authors are accountable for all remaining errors.

\section{Appendix A Supplementary data}

Supplementary data to this article can be found online at https://doi.org/10.1016/j.jasrep.2020.102232.

\section{References}

The corrections made in this section will be reviewed and approved by journal production editor.

Aldeias, V., 2017. Experimental approaches to archaeological fire features and their behavioral relevance. Curr. Anthropol. 58 (Suppl. 16), S191-S205.

Asouti, E., Austin, P., 2005. Reconstructing woodland vegetation and its exploitation by past societies, based on the analysis and interpretation of archaeological wood charcoal macroremains. Environ. Archaeol. 10, 1-18.

Astruc, J.-G., Coustou, J.-C., 1993. Aperçu géomorphologique et hydrologique du Causse de Gramat (1993/I/1). Bulletin de la Société d'études du Lot I (1), 1-10.

Badal García, E., 1990. Méthode de prélèvement et paléoécologie du Néolithique d'après les charbons de bois de "La Cova de les Cendres (Alicante, Espagne). Pact J. Eur. Study Group Phys. Chem. Math. 
Biol. Techniq. Appl. Archaeol. 22, 231-243.

Badal García, E., Heinz, C., 1991. Méthodes utilisées pour l'étude de sites préhistoriques. In: Waldren, W.H., Ensenyat J.A., Kennard R.C., eds. IInd Deya international conference of prehistory: vol. 1. Bar International Series 573: 17-47.

Barbaza, M., Valdeyron N., André J., Briois F., Martin H., Philibert S., Allios D., Lignon E., 1991. Fontfaurès-en-Quercy. Contribution à l'étude du Sauveterrien. Archives d'écologie préhistorique 11, Toulouse.

Bazile-Robert, E., 1982. Données expérimentales pour l'anthracoanalyse. Etudes Quaternaires languedociennes 2, 20-27.

Chabal, L., 1982. Méthodes de prélèvement des bois carbonisés protohistoriques pour l'étude des relations homme-végétation. D.E.A. (Master's Thesis) USTL, Montpellier.

Chabal, L., 1991. L'Homme et l'évolution de la végétation méditerranéenne des âges des métaux à la période romaine; recherches anthracologiques théoriques, appliquées principalement à des sites du BasLanguedoc. Unpubl. Ph.D. Thesis, Université de Montpellier 2.

Chabal, L., 1997. Forêts et sociétés en Languedoc (Néolihique final, Antiquité tardive). L'anthracologie, méthode et paléoécologie. Documents d'archéologie française 63, Éditions de la Maison des sciences de l'homme, Paris.

Chabal, L., Fabre, L., Terral, J.F., Théry-Parisot, I., 1999. L’Anthracologie, In: Ferdière, A. (Ed.), La botanique. Errance: Paris, 43-104.

Chrzavzez, J., 2013. Approche expérimentale de la conservation des charbons de bois dans les gisements paléolithiques : Processus post-dépositionnels, fragmentation et représentativité des assemblages anthracologiques. Ph.D. Thesis, Université de Nice Sophia Antipolis.

Chrzavzez, J., Théry-Parisot, I., Fiorucci, G., Terral, J.-F., Thibaut, B., 2014. Impact of post-depositional processes on charcoal fragmentation and archaeobotanical implications: experimental approach combining charcoal analysis and biomechanics. J. Archeol. Sci. 44, 30-42.

Delhon, C., Thiébault, S., 2009. De la forêt aux foyers paléolithiques et mésolithiques dans le Sud de la France : une revue des données anthracologiques et phytolithiques. In Théry-Parisot I., Costamagno S., Henry A. (eds.), Fuel Management during the Palaeolithic and Mesolithic Periods. New Tools, new interpretations. Proceedings of the XVth UISPP,Congress (Lisbon, 4-9 september 2006), BAR International Series 1914, Archaeopress: Oxford, 115-129.

Dussol, L., Elliott, M., Théry-Parisot, I., 2017. Experimental anthracology: evaluating the role of combustion processes in the representivity of archaeological charcoal records in tropical forests, a case study from the Maya Lowlands. J. Archaeol. Sci. Rep. 12, 480-490. 
Fabre, L., 1996. Le charbonnage historique de la chênaie à Quercus ilex L.: implications écologiques. Ph.D. Thesis, Université Montpellier II.

Heinz, C., 1988. Dynamique des végétations holocènes en Méditerrannée Nord-Occidentale d'après l'anthracoanalyse de sites préhistoriques : Méthodologie et paléoécologie. Ph.D. Thesis, Université des Sciences et Techniques du Languedoc, Montpellier.

Heinz, C., Thiébault, S., 1998. Characterization and Palaeoecological significance of archaeological charcoal assemblages during Late and Post-Glacial Phase in Southern France. Quat. Res. 50, 56-68.

Henry, A., 2011. Paléoenvironnements et gestion du bois de feu au Mésolithique dans le sud-ouest de la France : anthracologie, ethno-archéologie et expérimentation. Ph.D. Thesis, University of Nice-Sophia Antipolis. http://tel.archives-ouvertes.fr/tel-00726927. Accessed June 27, 2019.

Henry, A., Valdeyron, N., Bouby, L., Théry-Parisot, I., 2013. History and evolution of Mesolithic landscapes in the Haut Quercy (Lot, France): new charcoal data from archaeological contexts. The Holocene 23 (1), 127-136.

Henry, A., Boboeuf, M., 2016. Environnement ligneux et gestion du bois de feu au cours du Mésolithique au Clos de Poujol (Campagnac, Aveyron). Bulletin de la Société Préhistorique Française $113(1), 5-30$.

Henry, A., Théry-Parisot, I., 2014. From Evenk campfires to prehistoric hearths: charcoal analysis as a tool for identifying the use of rotten wood as fuel. J. Archaeol. Sci. 52, 321-336.

Krauss-Marguet, I., 1980. Contribution à l'histoire de la végétation postglaiciare des Grands Causses d'après l'analyse anthracologique du gisement préhistorique de la Poujade (commune de MillauAveyron). D.E.A. Université des Sciences et Techniques du Languedoc, Montpellier.

Lancelotti, C., Madella, M., Ajithprasad, P., Petrie, C.A., 2010. Temperature, compression and fragmentation: an experimental analysis to assess the impact of taphonomic processes on charcoal preservation. Archaeol. Anthropol. Sci. 2, 307-320.

Lavergne, D., 1963. Carte de végétation de la France n57. CNRS, Bergerac.

Ntinou, M., 2002. La Paleovegetación en el Norte de Grecia del Tardiglaciar hasta el Atlántico: formaciones vegetales, recursos y usos. BAR International Series 1038. Oxford: Archaeopress.

Pernaud, J.-M., 1992. L'interprétation paléoécologique des charbons concentrés dans les fossesdépotoirs protohistoriques du Carrousel (Louvre, Paris). Bulletin de la Société Botanique de France. Actualités Botaniques 139 (2-4), 329-341.

Reimer, P.J., Bard, E., Bayliss, A., Beck, J.W., Blackwell, P.G., Bronk Ramsey, C., Buck, C.E., Cheng, H., Edwards, R.L., Friedrich, M., Grootes, P.M., Guilderson, T.P., Haflidason, H., Hajdas, I., Hatté, C., Heaton, T.J., Hogg, A.G., Hughen, K.A., Kaiser, K.F., Kromer, B., Manning, S.W., Niu, M., Reimer, 
R.W., Richards, D.A., Scott, E.M., Southon, J.R., Turney, C.S.M., Van Der Plicht, J., 2013. IntCal13 and Marine13 Radiocarbon age calibration curves 0-50000 years cal BP. Radiocarbon 55 (4), 1869-1887.

Rivière, J., 2006. Approche archéozoologique des occupations du Mésolithique moyen et final des Escabasses (Thémines, Lot). Campagnes 1993-2002. Unpubl. Master Thesis, Muséum National d'Histoire Naturelle de Paris.

Smart, T.L., Hoffman, E.S., 1988. Environmental interpretation of archaeological charcoal. In: Hastorf, C.A., Popper, V.S. (Eds.), Current palaeoethnobotany. University of Chicago Press, Chicago \& London, pp. 165-205.

Théry-Parisot, I., 2001a. Economie des combustibles au Paléolithique. Dossier de Documentation Archéologique 20, Paris: CNRS Editions.

Théry -Parisot, I., 2001b. Analyse anthracologique de la grotte du Sanglier (Reilhac, Lot et Garonne). In: Seronie-Vivien, M. R. La grotte du sanglier à Reilhac (Lot). Du Magdalénien au Néolithique ancien. Préhistoire du Sud-Ouest 4: 93-99.

Théry-Parisot, I., 2002. The gathering of firewood during Palaeolithic time. In: Thiébault S. (ed.), Charcoal analyis, methodological approaches, palaeoecological results and wood uses. proceedings of the second international meeting of anthracology, Paris, September 2000. BAR International Series, 1063: 243-250.

Théry-Parisot, I., Henry, A., 2012. Seasoned or green? A new method to identify the use of green wood for fuel among archaeological charcoal. J Archaeol. Sci. 39 (2), 381-388.

Théry-Parisot, I., Chabal, L., Chrzavzez, J., 2010. Anthracology and taphonomy, from wood gathering to charcoal analysis. A review of the taphonomic processes modifying charcoal assemblages. Palaeogeogr. Palaeoclimatol. Palaeoecol. 291, 142-153.

Théry-Parisot, I., Chabal L., Ntinou M., Bouby L., Carré A., 2010b. From wood to wood charcoal: an experimental approach to combustion. I. Théry-Parisot, L. Chabal et, S. Costamagno (eds.). The taphonomy of burned organic residues and combustion features in archaeological contexts. Proceedings of the workshop, Valbonne, 27-29 mai 2008: P@lethnologie 2: 79-91.

Théry-Parisot, I., Henry, A., Chrzavzez J., 2016. Apport de l'expérimentation à la compréhension des pratiques sociétales en anthracologie : gestion et utilisation du bois de feu dans les sociétés préhistoriques. Cadernos do Lepaarq XIII (25).

Théry-Parisot, I., Thiebault, S., Delannoy, J.J., Ferrier, C., Feruglio, V., Fritz, C., Gely, B., Guibert, P., Monney, J., Tosello, G., Clottes, J., Geneste, J.-J., 2018. Illuminating the cave, drawing with black wood charcoal: new insights from la grotte Chauvet (Vallon-Pont d'Arc, France) through charcoal fragments analysis. Antiquity 92 (362), 320-333. 
Valdeyron, N., Carozza, J.-M., Gernigon, K., Peyrichoux, I., 1995. La grotte des Escabasses à Thémines (Lot). Rapport de fouille programmée (P. 10). Rapport intermédiaire $n^{\circ} 1$. Unpublished excavation Report, Toulouse, Université de Toulouse Le Mirail.

Valdeyron, N., Carozza, J.-M., Gernigon, K., 1996. La grotte des Escabasses à Thémines (Lot). Rapport de fouille programmée (P. 10). Unpubl. Excavation report, Toulouse, Université de Toulouse Le Mirail.

Valdeyron, N., 2000. Le gisement de la grotte des Escabasses à Thémines (Lot) et la séquence Mésolithique en Aquitaine. A. Richard, C. Cupillard, H. Richard, A. Thévenin, eds. Les derniers chasseurs-cueilleurs d'Europe occidentale (13000-5500 av. J.-C.). Actes du colloque international de Besançon 1998. Besançon, Presses Universitaires Franc-comtoises: 151-159.

Valdeyron, N., Bosc-Zanardo, B., Briand, T., Gernigon K., 2004. La grotte des Escabasses à Thémines (Lot). Rapport de fouille programmée (P. 10). Rapport final 2002. Unpubl. Excavation report, Toulouse, Université de Toulouse Le Mirail.

Valdeyron, N., Briand, T., Bouby, L., Henry, A., Khedhaier, R., Marquebielle, B., Martin, H., Thibeau, A., Bosc-Zanardo, B., 2011. The Mesolithic Site of Les Fieux (Miers, Lot): a Hunting Camp on the Gramat Karst Plateau? In: Bon, F., Costamagno, S., Valdeyron, N. (eds.), Hunting camps in prehistory. current archaeological approaches, proceedings of the international symposium, May 13-15, 2009, University Toulouse II - Le Mirail, P@lethnology 3: 331-341.

Vidal-Matutano, P., 2016. Around the fire: landscape, climate and firewood management in huntergatherer groups during the Middle Palaeolithic (Alicante, Spain). Ph.D. Thesis, Universitat de Valencia.

\section{Highlights}

- Archaeological charcoal taphonomy studies help understand different aspects ranging from human behavior to postdepositional processes affecting the assemblages.

- Early Mesolithic charcoal data from Escabasses site (SW France) was revisited.

- The impact of sample type (dispersed vs. concentrated) and fragment size (]2-4]mm vs. $>4 \mathrm{~mm}$ ) upon floristic diversity and oak abundance was investigated.

- Sample type did not affect floristic diversity nor the proportions between taxa.

- Fragment size did not impact floristic diversity but affected significantly main taxa frequencies.

- The great homogeneity of dispersed and concentrated charcoal samples may reflect specific Mesolithic behavior around fuel and fire. 


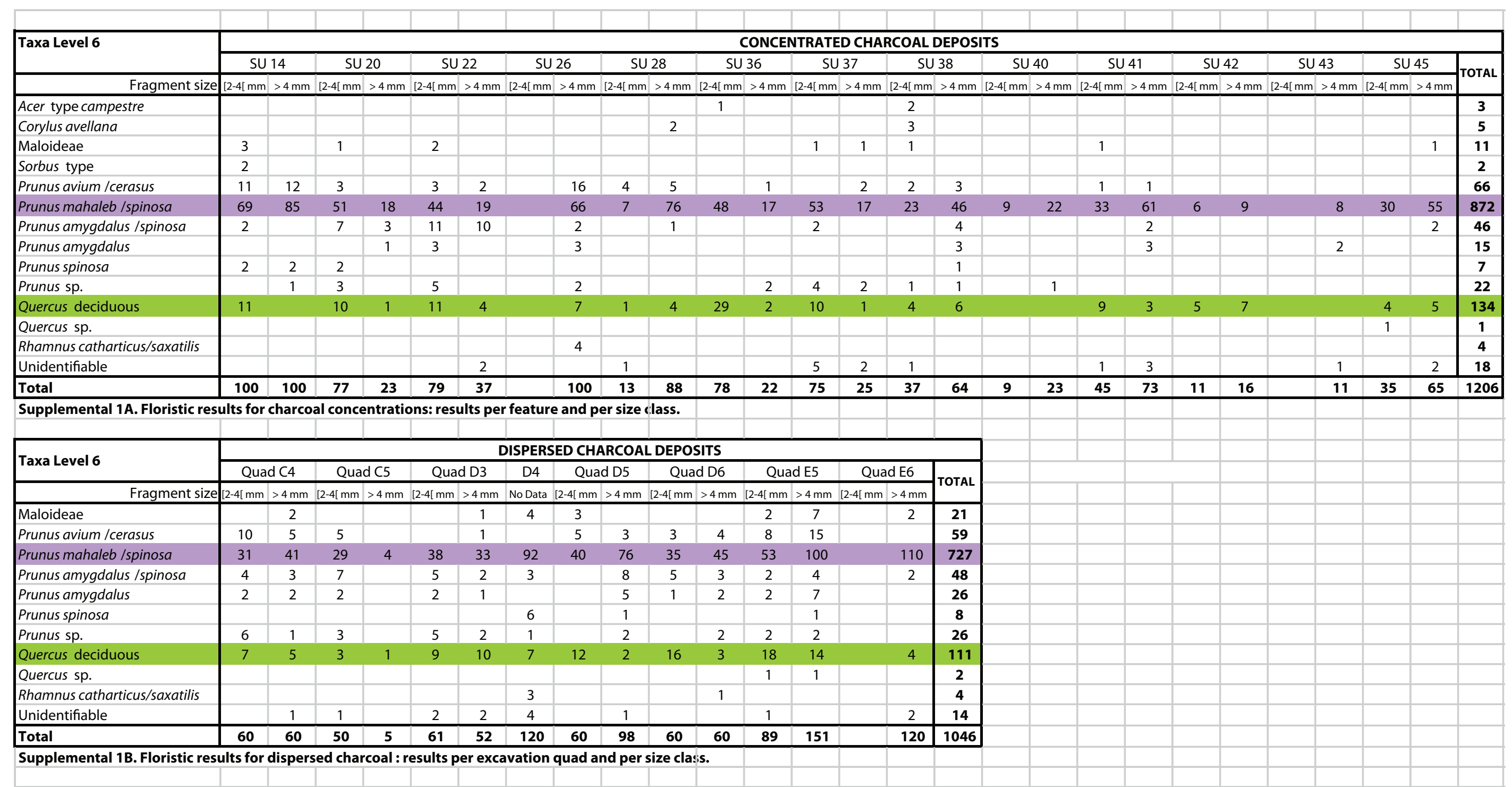




\section{Supplementary material 2- Correspondence (CA) and Hierarchical clustering (HCA) analyses: taxonomic results per sample}

We want to analyze the floristic dataset resulting from the anthracological analysis of different types of combustion features (SUs, concentrated charcoal) and of the charcoal fragments dispersed in the archaeological layer (Quads) from Escabasses Level 6. The objectives are:

1) to test if there are correspondences between different types of deposits/sampling contexts and

2) to understand if there are important differences at a structural level between samples that might reflect a spatial or a functional pattern.

The contingency table (Table A) displays the number of fragments identified for each taxon per quad and SU. In order to minimize the impact of extreme values potentially induced by different levels of taxonomic accuracy and overlapping, some taxa were regrouped into larger entities: Sorbus type was included in the Maloideae group, whereas Prunus amygdalus, P. spinosa and $P$. amygdalus/spinosa were regrouped within an undifferentiated $P$. amygdalus/mahaleb/spinosa category. Prunus spp. was not taken into account.

\begin{tabular}{|c|c|c|c|c|c|c|c|c|c|c|c|c|c|c|c|c|c|c|c|c|c|}
\hline & SU14 & SU20 & SU22 & SU26 & SU28 & SU36 & SU37 & SU38 & SU 40 & SU41 & SU 42 & SU43 & SU45 & $\mathrm{CA}_{4}$ & C5 & D3 & D4 & D5 & D6 & E5 & E6 \\
\hline Acer type campestre & & & & & & 1 & & 2 & & & & & & & & & & & & & \\
\hline Corylus avellana & & & & & 2 & & & 3 & & & & & & & & & & & & & \\
\hline Maloideae & 5 & 1 & 2 & & & & 2 & 1 & & 1 & & & 1 & 2 & & 1 & 4 & 3 & & 9 & 2 \\
\hline Prunus type avium & 23 & 3 & 5 & 16 & 9 & 1 & 2 & 5 & & 2 & & & & 15 & 5 & 1 & & 8 & 7 & 23 & \\
\hline Prunus amydgalus $/$ mahaleb $/$ spinosa & 160 & 82 & 87 & 71 & 84 & 65 & 72 & 77 & 31 & 99 & 15 & 10 & 87 & 83 & 42 & 81 & 101 & 130 & 91 & 169 & 112 \\
\hline Quercus deciduous & 11 & 11 & 15 & 7 & 5 & 31 & 11 & 10 & 1 & 12 & 12 & & 9 & 12 & 4 & 19 & 7 & 14 & 19 & 32 & 4 \\
\hline Rhamnus catharticus/saxatilis & & & & 4 & & & & & & & & & & & & & 3 & & 1 & & \\
\hline
\end{tabular}

Table A. Contingency table used for the Factor Analysis. Individuals with less than 50 fragments (highlighted in grey) were discarded.

\section{Results of the CA}

The CA, performed with the software Excel Stat, is based on a chi-square analysis. At the alpha significance level of $5 \%$, the results show that there is a correspondence between the rows and the columns of the table, i.e., that the distribution of at least one pair of values is not random.

\section{Test of independence between the rows and the columns:}

\begin{tabular}{|l|r|}
\hline Chi-square (Observed value) & 323,485 \\
\hline Chi-square (Critical value) & 126,574 \\
\hline DF & 102,000 \\
\hline p-value & $<0,0001$ \\
\hline alpha & 0,05 \\
\hline
\end{tabular}

\section{Interpretation:}

$\mathrm{HO}$ : The rows and the columns of the table are independent

$\mathrm{Ha}$ : there is a link between the rows and the columns of the table

As the computed $p$-value is lower than the significance level alpha=0,05, one should reject the null hypothesis $\mathrm{HO}$ and accept the alternative hypothesis $\mathrm{Ha}$.

Total inertia: 0,153 
Eigenvalues and percentages of inertia:

\begin{tabular}{|c|c|c|c|c|c|c|}
\hline & F1 & $1 ; 2$ & $\mathrm{~F} 3$ & $F 4$ & F5 & F6 \\
\hline Eigenvalue & 0,051 & 0,036 & 0,033 & 0,024 & 0,008 & 0,002 \\
\hline Inertia (\%) & 33,287 & 23,113 & 21,295 & 15,415 & 5,296 & 1,593 \\
\hline Cumulative \% & 33,287 & 56,401 & 77,695 & 93,111 & 98,407 & 100,000 \\
\hline
\end{tabular}

The cumulated percentages of inertia show that the inertia of axes F1 and F2 is satisfying (about $56 \%$ ). Axes F1 to F4 (highlighted in grey) were considered in order to reach the minimum of $80 \%$ allowing to fully comment the correspondences. Cumulating $93.1 \%$ of inertia, these axes explain almost all of the variability.

\section{Symmetric plots- rows and columns:}

As the alternative hypothesis Ha has to be accepted, the chi-square test indicates that there are correspondences between at least one row and one column. However, the aspect of the scree plots shows that we are not allowed to discuss most of our results (Figures A-C). Indeed, the majority of the dots (taxa, but especially samples) are regrouped around the axes' intersections, which means that their contributions to the analysis are very low.

Within the rows (taxa), the dots whose coordinates are far enough from the origin and, thus, discussable, are the ones corresponding to Acer, Corylus, Rhamnus, P. type avium, and Quercus. Within the columns (samples), only a few seem to contribute significantly to the axes: SUs 26, 36, 38 and, to a lesser extent, quads C4 and D4.

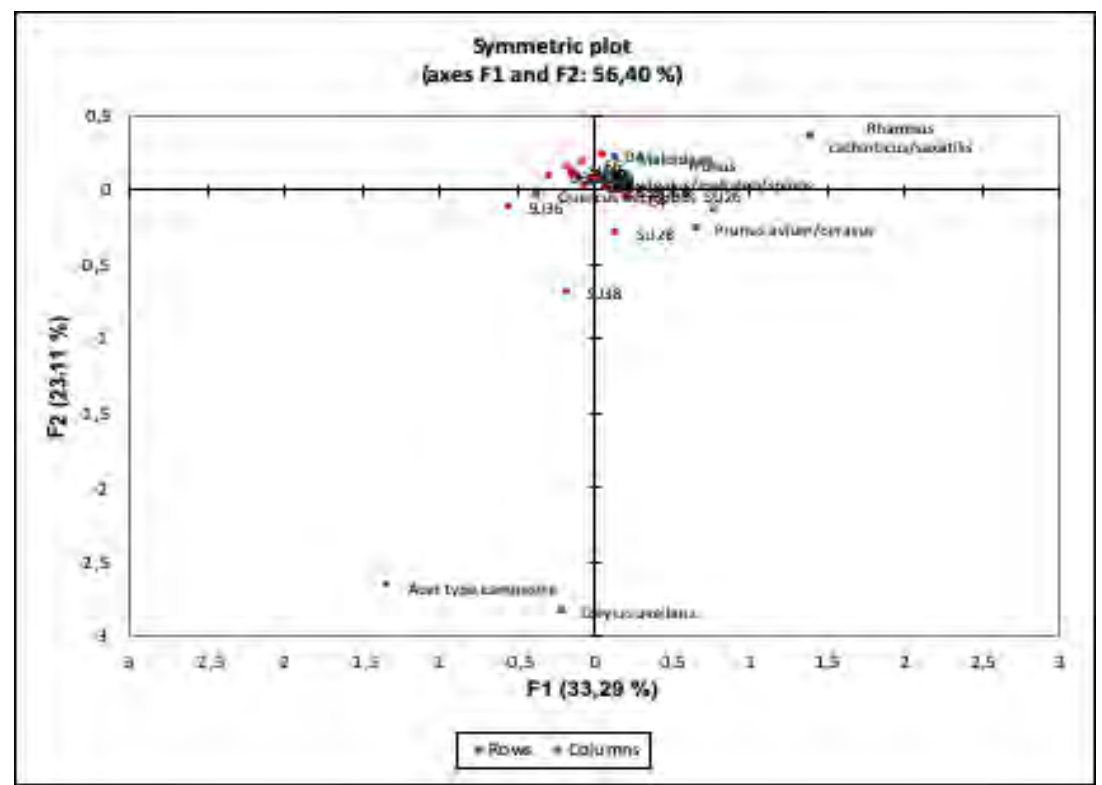

Figure A. Symmetric plot: axes F1 and F2. 


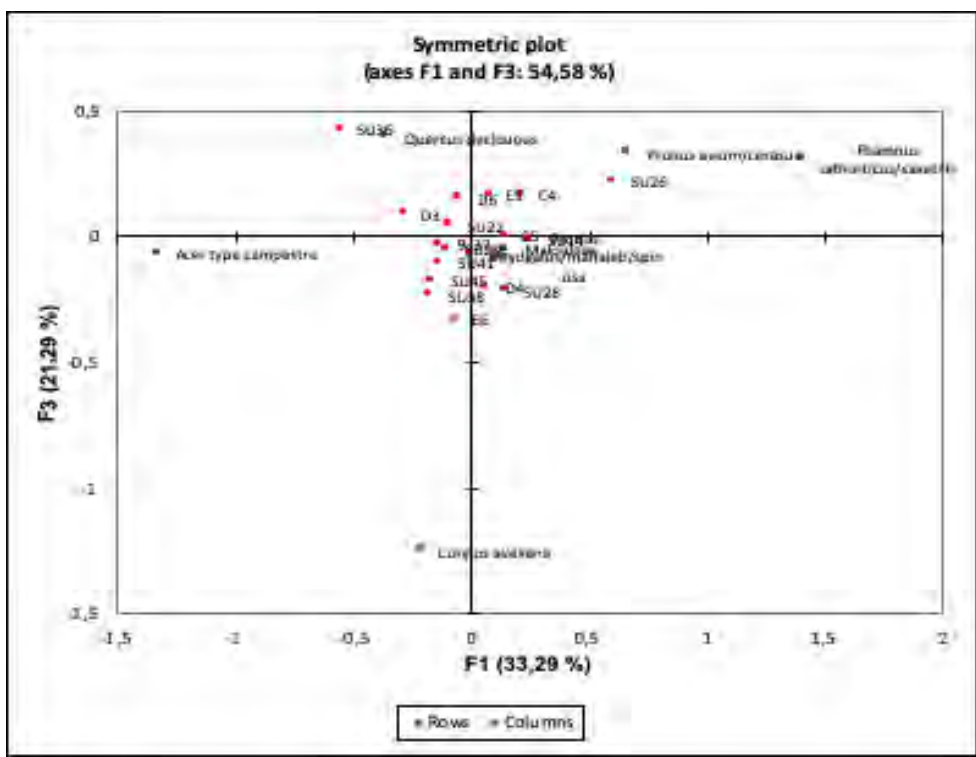

Figure B. Symmetric plot: axes F1 and F3.

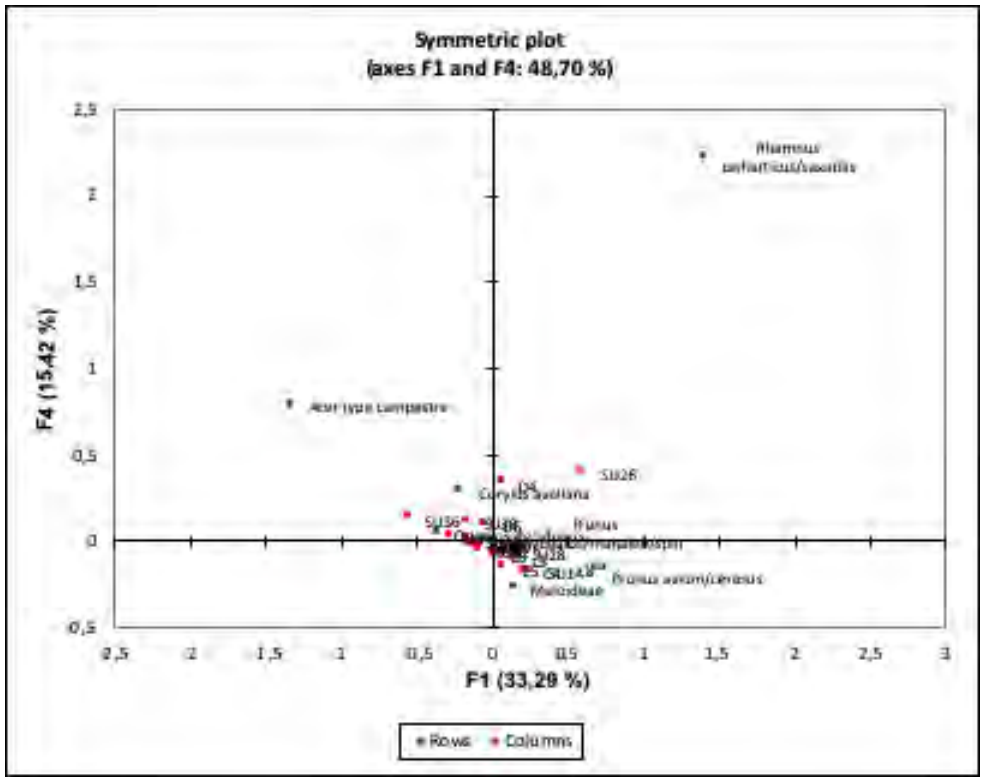

Figure C. Symmetric plot: axes F1 and F4.

\section{Contributions- rows and columns:}

The taxon with the most important weight (Table B- highlighted in dark grey), Prunus amygdalus/mahaleb/spinosa, has only a marginal contribution (axis F3); the same can be said about Maloideae, a group that has a much lower weight but whose contribution to the observed variability is not significant.

\begin{tabular}{lrrrrrrr}
\hline & Weight (relative) & \multicolumn{1}{l}{ F1 } & F2 & F3 & F4 & F5 & F6 \\
\hline Acer type campestre & 0,001 & 0,049 & 0,284 & 0,000 & 0,037 & 0,091 & 0,537 \\
Corylus avellana & 0,002 & 0,002 & 0,538 & 0,113 & 0,008 & 0,000 & 0,336 \\
Maloideae & 0,016 & 0,007 & 0,021 & 0,001 & 0,049 & 0,865 & 0,040 \\
Prunus avium/cerasus & 0,059 & 0,512 & 0,115 & 0,203 & 0,097 & 0,007 & 0,007 \\
\hline Prunus amydgalus/mahaleb/spinosa & 0,806 & 0,001 & 0,023 & 0,142 & 0,000 & 0,018 & 0,011 \\
Quercus deciduous & 0,111 & 0,283 & 0,005 & 0,530 & 0,010 & 0,000 & 0,061 \\
Rhamnus catharticus/saxatilis & 0,004 & 0,146 & 0,013 & 0,011 & 0,799 & 0,019 & 0,009 \\
\hline
\end{tabular}

Table B. Contributions of the rows (taxa). 
The presence and proportions of these two taxa are quite constant within the samples which, from an anthracological viewpoint, can already be interpreted as a sign of homogeneity: the dominant taxon dominates each sample and there is a quite ubiquitous secondary taxon. In light of this, what can be said about the variability factors?

The contributions of the rows show that the main contribution to axis F1 is represented by Prunus type avium and, to a lesser extent, by Quercus, while SU 26 and SU 36 are the main contributors to the columns (see Table $\mathbf{C}$, light grey).

\begin{tabular}{lrllllll}
\hline & Weight (relative) & $F 1$ & $F 2$ & $F 3$ & $F 4$ & $F 5$ & $F 5$ \\
\hline SU14 & 0,095 & 0,112 & 0,000 & 0,000 & 0,116 & 0,007 & 0,105 \\
SU20 & 0,046 & 0,010 & 0,010 & 0,004 & 0,001 & 0,020 & 0,001 \\
SU22 & 0,052 & 0,009 & 0,006 & 0,003 & 0,004 & 0,000 & 0,011 \\
SU26 & 0,047 & 0,326 & 0,002 & 0,072 & 0,327 & 0,030 & 0,013 \\
SU28 & 0,048 & 0,019 & 0,116 & 0,067 & 0,007 & 0,143 & 0,417 \\
SU36 & 0,047 & 0,278 & 0,017 & 0,261 & 0,037 & 0,001 & 0,038 \\
SU37 & 0,041 & 0,016 & 0,013 & 0,001 & 0,001 & 0,008 & 0,011 \\
SU38 & 0,047 & 0,028 & 0,635 & 0,077 & 0,025 & 0,061 & 0,046 \\
SU41 & 0,054 & 0,019 & 0,019 & 0,018 & 0,000 & 0,032 & 0,005 \\
SU45 & 0,046 & 0,024 & 0,027 & 0,043 & 0,000 & 0,018 & 0,007 \\
C4 & 0,053 & 0,048 & 0,006 & 0,045 & 0,062 & 0,004 & 0,013 \\
C5 & 0,024 & 0,009 & 0,000 & 0,000 & 0,010 & 0,071 & 0,050 \\
D3 & 0,049 & 0,076 & 0,012 & 0,012 & 0,002 & 0,012 & 0,066 \\
D4 & 0,055 & 0,004 & 0,078 & 0,066 & 0,266 & 0,223 & 0,030 \\
D5 & 0,074 & 0,000 & 0,011 & 0,009 & 0,015 & 0,000 & 0,009 \\
D6 & 0,056 & 0,003 & 0,001 & 0,040 & 0,023 & 0,087 & 0,011 \\
E5 & 0,111 & 0,013 & 0,000 & 0,096 & 0,103 & 0,281 & 0,089 \\
E6 & 0,056 & 0,005 & 0,047 & 0,184 & 0,000 & 0,002 & 0,078 \\
\hline
\end{tabular}

Table C. Contributions of the columns (samples).

These two taxa represent the main secondary taxa; they are more ubiquitous and frequent than Maloideae, but their range of frequencies shows higher variability; SU 26 corresponds to the sample where Prunus type avium is the most abundant (16\%), while Quercus values are the highest in SU 36 (31\%). Axis F2 is mainly defined by the contribution of Corylus and Acer, as well as SU 38, which yielded the highest number of fragments of these taxa (5\% of the sample). From the viewpoint of charcoal analysis, these taxa representing less than $1 \%$ of the total are considered as rare (i.e., secondary in the vegetation, rarely collected, whose presence in the spectrum is thus sporadic and subjected to sampling hazards). As main contributors to axis F3, we find again Quercus associated to SU 36, whereas quad E6, which also contributes to F3, is separated from the first two by axis F1; this is not really surprising as it yielded the lowest Quercus percentages (3.4\%). Finally, axis F4 benefits from a strong contribution of Rhamnus, which also falls into the "rare taxa" category; unsurprisingly, the samples that contribute to this axis are those containing Rhamnus (quad D4 and SU 26).

In sum, the variability within rows and columns can be explained by two main causes:

- "Extreme" values in the frequencies of ubiquitous, secondary taxa (Prunus type avium and Quercus), mostly recorded in 3 samples (SU26, SU36, E6).

- The presence of rare taxa which have the lowest relative weights (Corylus, Acer and Rhamnus), mostly recorded in 3 samples (SU26, SU38, D4).

Thus, the overall variability appears quite low, with only 4 samples out of 18 contributing to it. Furthermore, none of these samples can be regarded as outliers from an anthracological viewpoint, as in all of them, the global hierarchy between taxa is respected (Prunoideae dominant, Quercus secondary, Maloideae recurrent), while rare taxa are per definition sporadic in the record and provide important complementary ecological information.

In order to evidence the dissimilarities between samples, a hierarchical clustering analysis (HCA) was made on the coordinates of the columns (quads and SUs - Table E). 


\begin{tabular}{|l|r|r|r|r|r|r|}
\hline & $F 1$ & $F 2$ & \multicolumn{1}{l|}{$F 3$} & \multicolumn{1}{l}{$F$ 4 } & \multicolumn{1}{c|}{$F 5$} & \multicolumn{1}{l|}{$F 6$} \\
\hline SU14 & 0,246 & $-0,007$ & $-0,009$ & $-0,171$ & 0,025 & $-0,052$ \\
\hline SU20 & $-0,106$ & 0,088 & $-0,052$ & $-0,019$ & $-0,059$ & $-0,008$ \\
\hline SU22 & $-0,094$ & 0,063 & 0,046 & $-0,045$ & 0,003 & 0,022 \\
\hline SU26 & 0,599 & $-0,043$ & 0,225 & 0,408 & $-0,072$ & $-0,026$ \\
\hline SU28 & 0,144 & $-0,294$ & $-0,214$ & $-0,058$ & $-0,156$ & 0,147 \\
\hline SU36 & $-0,553$ & $-0,114$ & 0,429 & 0,137 & $-0,012$ & $-0,045$ \\
\hline SU37 & $-0,141$ & 0,108 & $-0,034$ & $-0,027$ & 0,040 & 0,026 \\
\hline SU38 & $-0,175$ & $-0,696$ & $-0,233$ & 0,113 & 0,104 & $-0,049$ \\
\hline SU41 & $-0,133$ & 0,110 & $-0,104$ & $-0,002$ & $-0,069$ & $-0,015$ \\
\hline SU45 & $-0,165$ & 0,144 & $-0,176$ & 0,014 & $-0,056$ & $-0,019$ \\
\hline C4 & 0,214 & $-0,063$ & 0,166 & $-0,166$ & $-0,023$ & $-0,024$ \\
\hline C5 & 0,141 & $-0,013$ & 0,007 & $-0,097$ & $-0,155$ & $-0,071$ \\
\hline D3 & $-0,283$ & 0,092 & 0,090 & 0,030 & $-0,045$ & 0,058 \\
\hline D4 & 0,064 & 0,225 & $-0,199$ & 0,340 & 0,182 & 0,037 \\
\hline D5 & $-0,002$ & 0,073 & $-0,064$ & $-0,068$ & 0,001 & $-0,018$ \\
\hline D6 & $-0,051$ & 0,030 & 0,153 & 0,099 & $-0,113$ & 0,022 \\
\hline E5 & 0,077 & 0,001 & 0,168 & $-0,149$ & 0,144 & 0,044 \\
\hline E6 & $-0,068$ & 0,173 & $-0,328$ & $-0,014$ & $-0,017$ & $-0,058$ \\
\hline
\end{tabular}

Table E. Principal coordinates of the columns established by the FA.

\section{Results of the HCA}

The aspect of the level diagram (Figure D) calls for a partition into four classes, explaining about $50 \%$ of the inter-class variance (Table F).

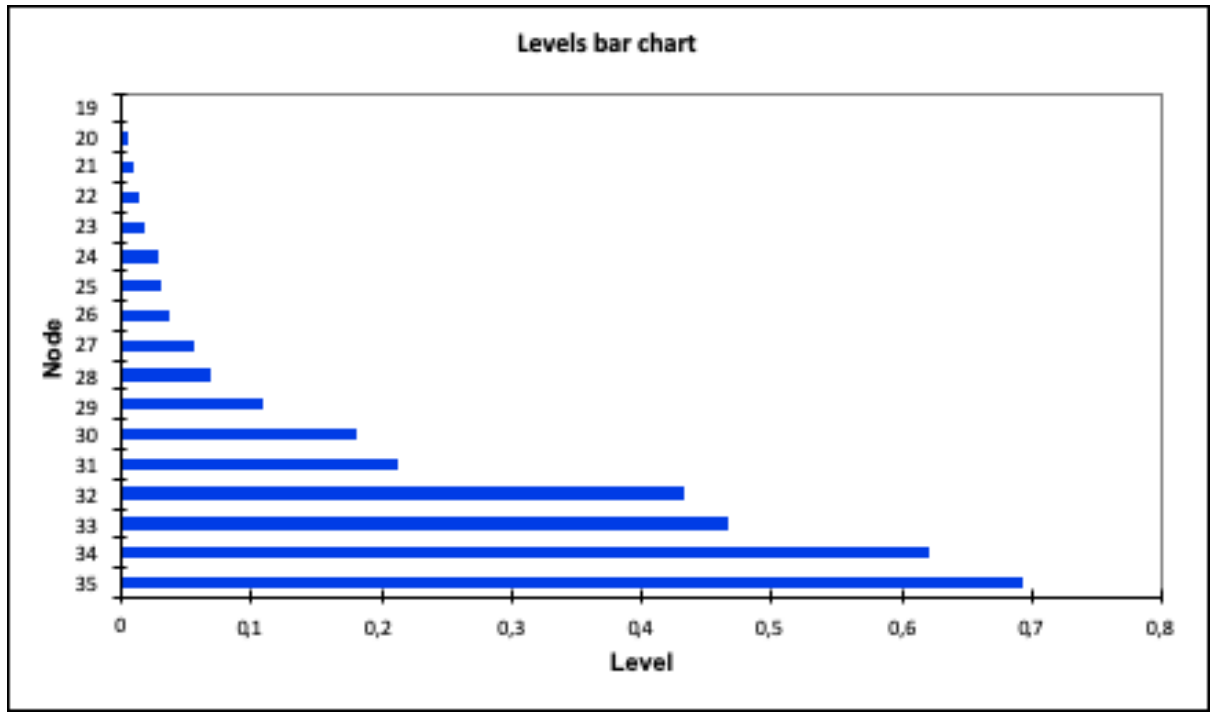

Figure D. Hierarchical clustering: levels bar chart.

\begin{tabular}{|l|r|r|}
\hline & Absolute & Percent \\
\hline Within-class & 0,086 & $49,12 \%$ \\
\hline Between-classes & 0,089 & $50,88 \%$ \\
\hline Total & 0,176 & $100,00 \%$ \\
\hline
\end{tabular}

Table $\mathbf{F}$. Variance decomposition for adequate classification.

The resulting dendrogram (Figure E) confirms the specific status of SUs 36 and 38, isolated from the rest of the samples by the first knot. They are however, dissimilar, as they are classified into two groups, one characterized by high Quercus values and presence of Acer (SU 36), the other one characterized by the presence of Acer and Corylus (SU 38). However, we already saw that from an anthracological viewpoint the contents of these two SUs are not abnormal. 


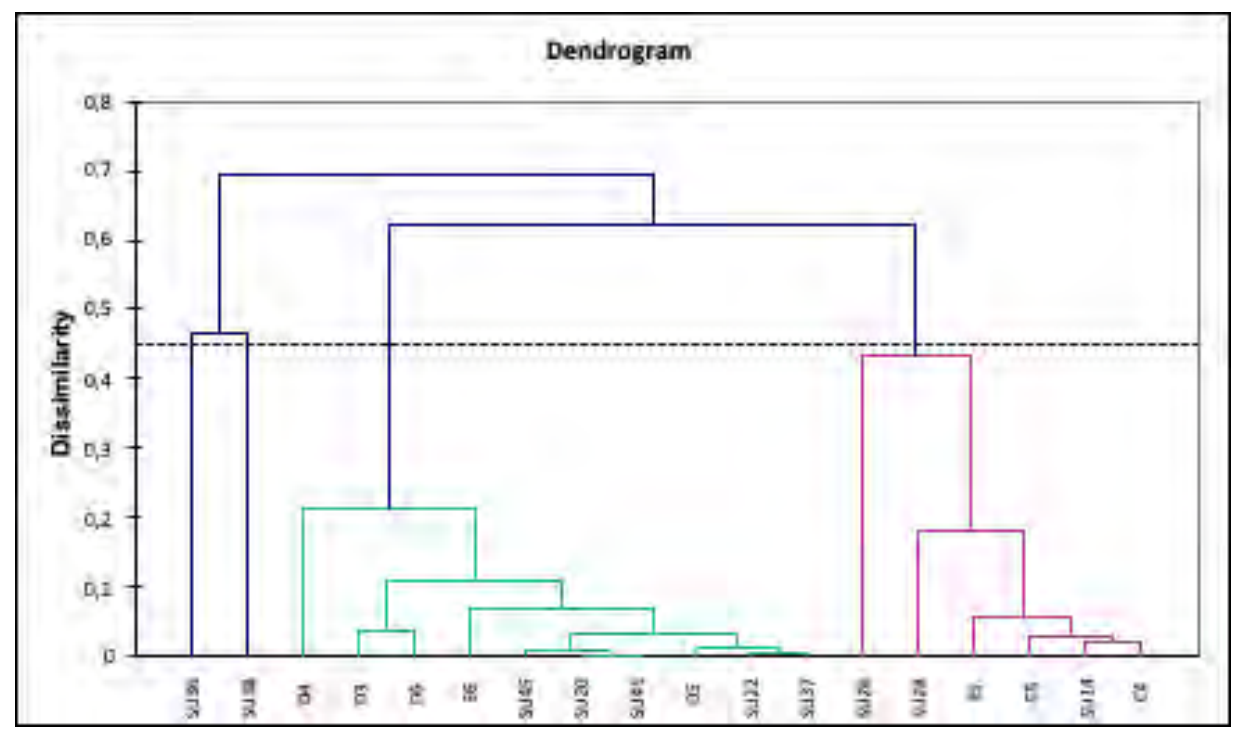

Figure E. HCA: Dendrogram.

More interestingly, the rest of the values divides into two groups, which are separated on the basis of the abundance of bird cherry, Prunus type avium; the first group, composed by 10 objects, has bird cherry frequencies below $6 \%$, while the second one, composed by 6 objects, shows higher frequencies (between 9 and 16\%). The variance within this last class is higher than within the former (Table G) due to the presence of SU 26, of which we saw that it stands out due to the contribution of Rhamnus.

\begin{tabular}{|c|c|c|c|c|c|c|}
\hline Class & 1 & 2 & 3 & 4 & & \\
\hline Objects & 6 & 10 & 1 & 1 & & \\
\hline Sum of weights & 6 & 10 & 1 & 1 & & \\
\hline Within-class variance & 0,144 & 0,054 & 0,000 & 0,000 & & \\
\hline Minimum distance to centroid & 0,172 & 0,074 & 0,000 & 0,000 & & \\
\hline Average distance to centroid & 0,310 & 0,193 & 0,000 & 0,000 & 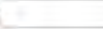 & \\
\hline \multirow[t]{10}{*}{ Maximum distance to centroid } & 0,601 & 0,438 & 0,000 & 0,000 & & \\
\hline & 5014 & SU20 & su36 & SU38 & & \\
\hline & 5426 & SU22 & & & & \\
\hline & 5428 & SU37 & & & & \\
\hline & CA & SU41 & & & & \\
\hline & $C 5$ & SU45 & & & \multicolumn{2}{|c|}{ Interpretation: } \\
\hline & E5 & D3 & & & SU36 & \multirow{2}{*}{$\begin{array}{l}\text { Highest oak values } \\
\text { Two rare taxa }\end{array}$} \\
\hline & & D4 & & & SU38 & \\
\hline & & D5 & & & SU20 & Bird cherry recurrent \\
\hline & & D6 & & & $5 \cup 14$ & Bird cherry secondary \\
\hline & & E6 & & & SU26 & Buckthorn highest \\
\hline
\end{tabular}

Table G. Results by class and summary of the differences.

\section{Conclusion:}

The HCA confirms that the variability between samples is relative from an anthracological viewpoint, as it is mainly dependent upon the fluctuating contributions of secondary taxa to the floristic richness, while the global signal -preponderance of Prunoideae and secondary importance of oak- is equivalent between quads and features. Interestingly, for classes composed of more than two individuals, groups include quads as well as SUs, which means that the contents of scattered vs. concentrated charcoal samples are comparable, although it seems that extreme values (rare taxa, oak frequencies) are more prone to be found in the SUs. 


\section{Supplementary Material 3. Tests on contingency tables: impact of sampling context and size upon global Prunus and Quercus values}

\section{Objectives:}

we want to analyze the co-variations between the frequencies of the two main taxa, Prunoideae and deciduous oak, in order to know if these frequencies are affected by (i) sample type (charcoal concentrated in features or dispersed within the archaeological level); (ii) fragment size (smaller vs. larger fragments over $4 \mathrm{~mm}$ ).

\section{A. Contingency tables tests: dispersed (quad) vs. concentrated (SU) charcoal}

Dataset: number of analyzed fragments attributed to Prunus spp. or Quercus, for Quads and SUs.

\begin{tabular}{|l|r|r|}
\hline & total SU & total Quad \\
\hline Prunus spp. & 1028 & 894 \\
\hline Quercus & 135 & 113 \\
\hline
\end{tabular}

Significance level alpha chosen for the test: 0,025

Chi-square test:

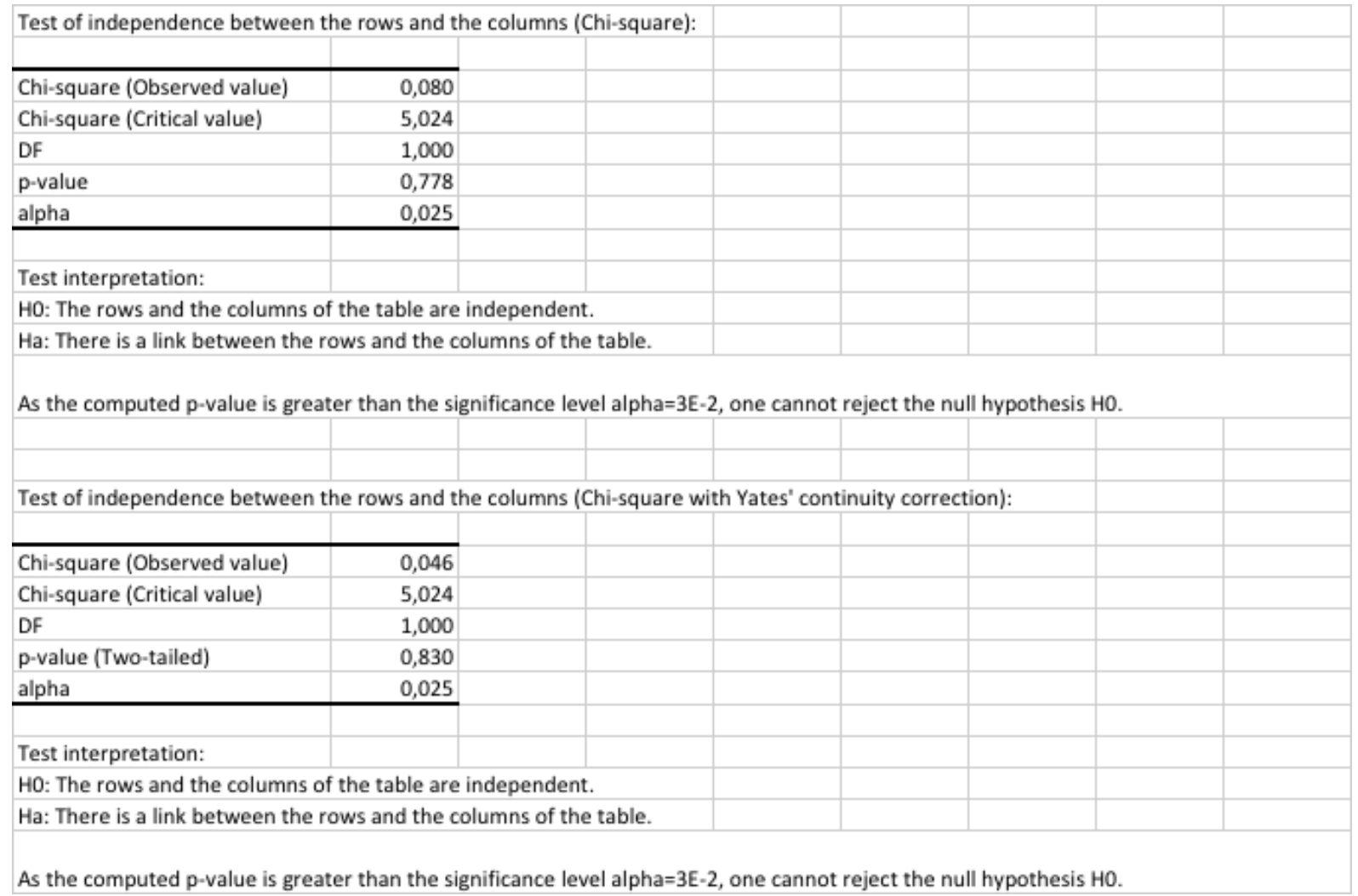

Interpretation: The values of Prunus spp. and Quercus do not seem to vary according to sample type; the p-value is higher than the chosen significance level and the chi-square values by cell are much lower than the critical value (Table A.). 


\begin{tabular}{|l|r|r|r|}
\hline Chi-square by cell: & & & \\
\hline & \multicolumn{1}{|c|}{ total SU } & total Quad & \multicolumn{1}{|c|}{ Total } \\
\hline Prunus spp. & 0,004 & 0,005 & 0,009 \\
\hline Quercus & 0,033 & 0,038 & 0,071 \\
\hline Total & 0,037 & 0,043 & 0,080 \\
\hline \multicolumn{2}{|c}{ Table $A}$.
\end{tabular}

Fisher's exact test and Pearson's residuals come to the same conclusions:

\begin{tabular}{l}
\begin{tabular}{|l|c|c|}
\hline \multicolumn{2}{|l|}{ Significance by cell (Fisher's exact test): } & \\
\hline & total SU & total Quad \\
\hline Prunus spp. & $<$ & $>$ \\
\hline Quercus & $>$ & $<$ \\
\hline Values displayed in red are significant at the level alpha $=0,025$ \\
\hline
\end{tabular} \\
\hline
\end{tabular}

\begin{tabular}{|l|r|r|}
\hline Residuals (Pearson): & & \\
\hline & & \\
\hline Prunus spp. & total SU & total Quad \\
\hline Quercus & $-0,065$ & 0,070 \\
\hline & 0,181 & $-0,194$ \\
\hline & & \\
\hline Residuals (Adjusted): & & \\
\hline & & \\
\hline & total SU & total Quad \\
\hline Prunus spp. & $-0,282$ & 0,282 \\
\hline Quercus & 0,282 & $-0,282$ \\
\hline Values displayed in bold are significant at the level alpha $=0,025$ \\
\hline
\end{tabular}




\section{B. Contingency tables tests: $] 2-4[\mathrm{~mm}$ vs. $>4 \mathrm{~mm}$ charcoal}

Dataset: number of analyzed fragments attributed to Prunus spp. or Quercus, per size class.

\begin{tabular}{|l|r|r|}
\hline & ] $2-4[\mathrm{~mm}$ & $>4 \mathrm{~mm}$ \\
\hline Prunus & 744 & 1076 \\
\hline Quercus & 161 & 79 \\
\hline
\end{tabular}

Significance level alpha chosen for the test: 0,025

Chi-square test:

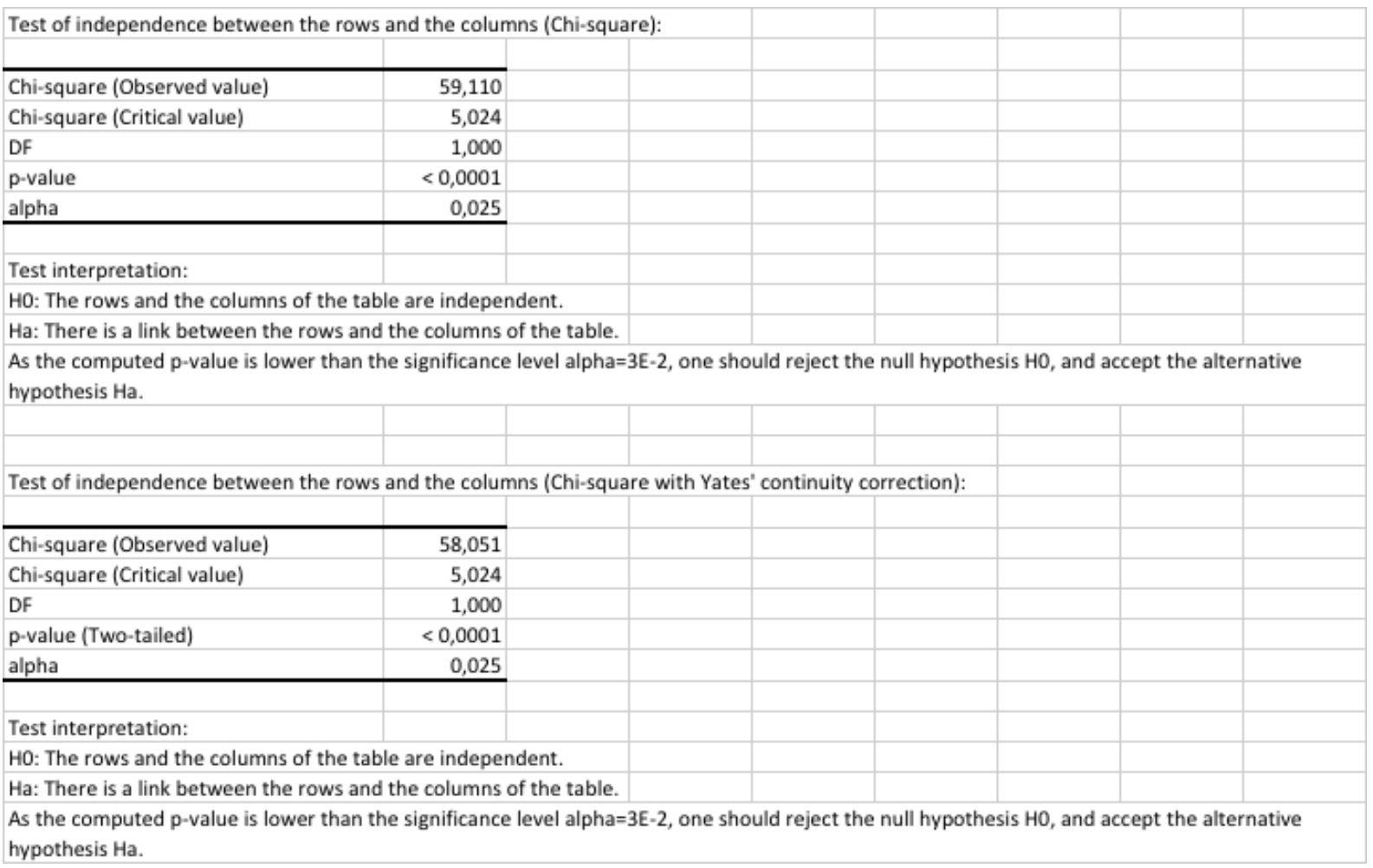

Interpretation: The extremely low p-value, as well as the simplicity of the table (1 degree of freedom) and the high effectives provide a high statistical significance to the results of this test i.e., at least one row and one column of the contingency table are strongly related to one another. The chi-square by cell (table B) indicates that there are actually two cells that are clearly above the critical value.

\begin{tabular}{l|r|r|r|}
\hline Chi-square by cell: & & \\
\hline & $12-4[\mathbf{m m}$ & $>4 \mathbf{m m}$ & \multicolumn{1}{c|}{ Total } \\
\hline Prunus & 3,86 & 3,03 & 6,89 \\
\hline Quercus & $\mathbf{2 9 , 2 8}$ & $\mathbf{2 2 , 9 4}$ & 52,22 \\
\hline Total & 33,14 & 25,97 & 59,11 \\
\hline \multicolumn{3}{l}{ Table B. }
\end{tabular}

These correspond to the Quercus values, which means that the variations in the number of fragments identified as Quercus within the larger or the smaller size fractions are not random: the effect of size class on the values of this taxon is strongly significant. On the opposite, the 
chi-square test may not consider the effect of size class significant in the case of Prunus spp., as the effective of this taxon is much higher and thus, its relative fluctuations are less important.

Fisher's exact test and Pearson's residuals confirm this result and suggest that Prunus spp. values are also dependent:

\begin{tabular}{l}
\hline Fisher's exact test: \\
\hline \begin{tabular}{l|l|l|}
\hline p-value (Two-tailed) \\
\hline alpha \\
\hline
\end{tabular} \\
\hline Test interpretation: \\
\hline H0: The rows and the columns of the table are independent. \\
\hline Ha: There is a link between the rows and the columns of the table. \\
\hline $\begin{array}{l}\text { As the computed p-value is lower than the significance level alpha=3E-2, one should reject the null hypothesis H0, and accept the alternative } \\
\text { hypothesis Ha. }\end{array}$ \\
\hline
\end{tabular}

It is not surprising that Fisher's exact test is also highly significant, as it is less robust than the chi-square test. However, its results confirm that within the $4 \mathrm{~mm}$ size fraction, Quercus values are lower than expected and Prunus values are concomitantly higher, while it is the opposite in the smaller size fraction:

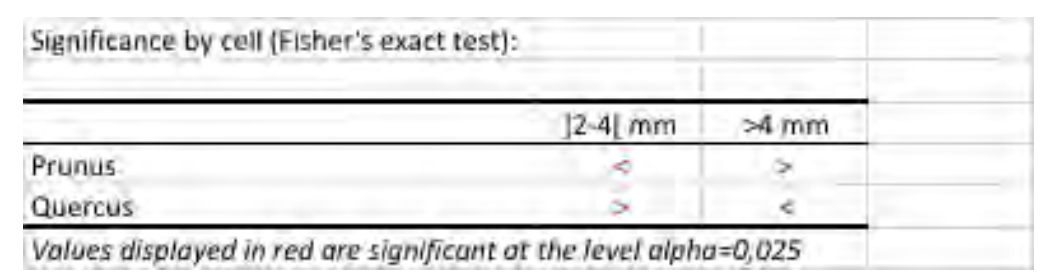

With values over 2 or -2 (in bold), Pearson's residuals complete the picture by confirming that the observed Quercus values are significant and specify that they are negatively associated according to the size class:

\begin{tabular}{|l|r|r|}
\hline Residuals (Pearson): & & \\
\hline & & \\
\hline & $12-4[\mathrm{~mm}$ & \multicolumn{1}{c|}{$>4 \mathrm{~mm}$} \\
\hline Prunus & $-1,965$ & 1,739 \\
\hline Quercus & $\mathbf{5 , 4 1 1}$ & $\mathbf{- 4 , 7 9 0}$ \\
\hline
\end{tabular}

The table of adjusted residues shows that there is a dependence between Quercus, but also Prunus values according to size class:

\begin{tabular}{|l|r|r|}
\hline Residuals (Adjusted): & \\
\hline & & \\
\hline & ] $2-4[\mathrm{~mm}$ & $>4 \mathrm{~mm}$ \\
\hline Prunus & $\mathbf{- 7 , 6 8 8}$ & $\mathbf{7 , 6 8 8}$ \\
\hline Quercus & $\mathbf{7 , 6 8 8}$ & $\mathbf{- 7 , 6 8 8}$ \\
\hline Values displayed in bold are significant at the level alph $=0,025$
\end{tabular}




\section{C. Contingency tables tests: $>2 \mathrm{~mm}$ vs. $>4 \mathrm{~mm}$ charcoal}

Dataset: number of analyzed fragments attributed to Prunus spp. or Quercus, per size class (larger than $2 \mathrm{~mm}$ vs. larger than $4 \mathrm{~mm}$ ).

\begin{tabular}{|l|r|r|}
\hline & $>2 \mathrm{~mm}$ & $>4 \mathrm{~mm}$ \\
\hline Prunus & 1922 & 1076 \\
\hline Quercus & 248 & 79 \\
\hline
\end{tabular}

Significance level alpha chosen for the test: 0,025

The Mc Nemar test, used to detect the effect of a treatment on two paired samples, indicates that the study of charcoal fragments larger than $4 \mathrm{~mm}$ yields different results than the study of charcoal fragments over $2 \mathrm{~mm}$ (which include the former category), at least in what regards the frequencies of the two main taxa.

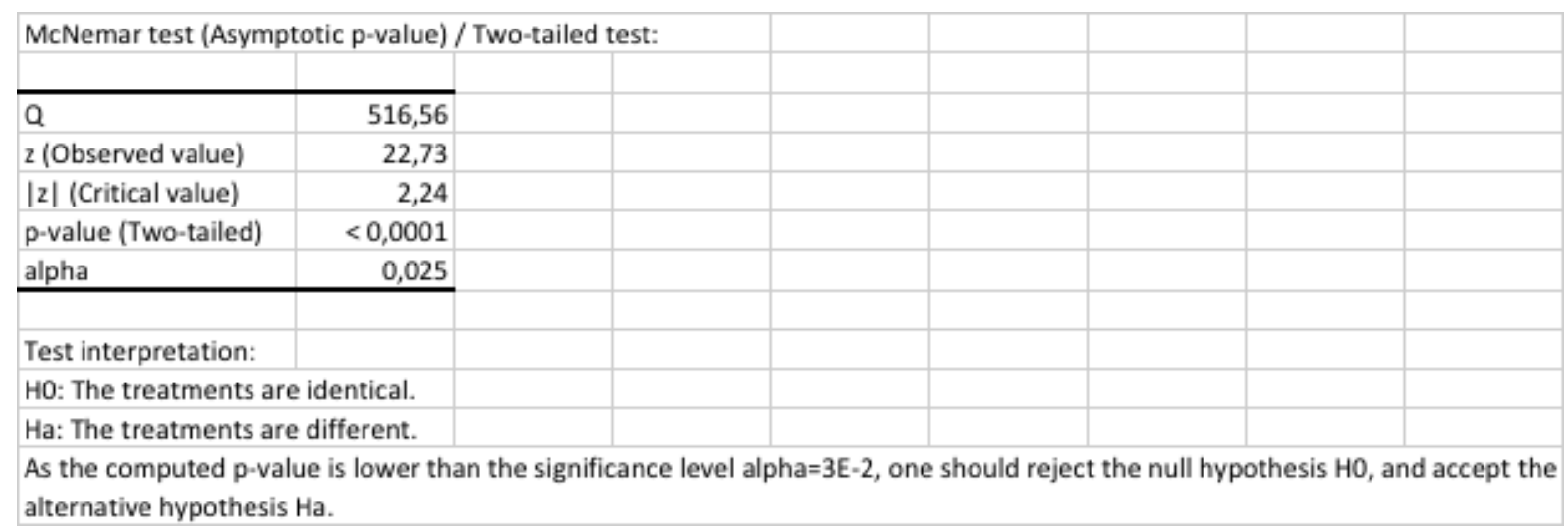




\section{Supplementary Material 4: Spearman correlation tests. number of identified taxa per number of observed fragments}

Dataset: number of analyzed fragments and number of identified taxa, per size class, sampling context and total values.

\begin{tabular}{|c|c|c|c|c|c|c|}
\hline Sample & $\mathbf{n}[\mathbf{2 - 4}[\mathbf{~ m m}$ & $\mathbf{n r}$. of taxa & $\mathbf{n}>\mathbf{4} \mathbf{~ m m}$ & $\mathbf{n r}$. of taxa & $\mathbf{n}$ total & $\mathbf{n}$ taxa total \\
\hline quad C4 & 60 & 6 & 60 & 7 & 120 & 7 \\
\hline quad C5 & 50 & 6 & 5 & 2 & 55 & 6 \\
\hline quad D3 & 61 & 5 & 52 & 7 & 113 & 7 \\
\hline quad D4 & no data & no data & no data & no data & 120 & 7 \\
\hline quad D5 & 60 & 4 & 98 & 7 & 158 & 8 \\
\hline quad D6 & 60 & 5 & 60 & 7 & 120 & 6 \\
\hline quad E5 & 89 & 8 & 151 & 9 & 240 & 9 \\
\hline quad E6 & 0 & 0 & 120 & 4 & 120 & 4 \\
\hline SU 14 & 100 & 7 & 100 & 4 & 200 & 8 \\
\hline SU 20 & 77 & 7 & 23 & 4 & 100 & 8 \\
\hline SU 22 & 79 & 7 & 37 & 4 & 116 & 7 \\
\hline SU 26 & 0 & 0 & 100 & 7 & 100 & 7 \\
\hline SU 28 & 13 & 4 & 88 & 5 & 101 & 5 \\
\hline SU 36 & 78 & 3 & 22 & 4 & 100 & 5 \\
\hline SU 37 & 75 & 5 & 25 & 5 & 100 & 6 \\
\hline SU 38 & 37 & 7 & 64 & 8 & 101 & 10 \\
\hline SU 40 & 9 & 1 & 23 & 2 & 32 & 2 \\
\hline SU 41 & 45 & 5 & 73 & 5 & 118 & 6 \\
\hline SU 42 & 11 & 2 & 16 & 2 & 27 & 2 \\
\hline SU 43 & 0 & 0 & 11 & 2 & 11 & 2 \\
\hline SU 45 & 35 & 3 & 65 & 5 & 100 & 5 \\
\hline Theoretical & 0 & 0 & 0 & 0 & 0 & 0 \\
\hline individual & 0 & 0 & 0 & & & \\
\hline & & & & & & \\
\hline
\end{tabular}

The row "theoretical individual" was added so that all correlation lines have a $0 ; 0$ origin. Significance level alpha chosen for the tests: 0,025 .

\section{A. Spearman correlation test, all samples ( $n$ total) and $n$ taxa total}

\begin{tabular}{|c|c|c|c|c|c|c|c|c|}
\hline \multicolumn{8}{|c|}{ Summary statistics (Quantitative data): } & \\
\hline Variable & Observations & Obs. with missing data & Obs. without missing data & Minimum & Maximum & Mean & Std. deviation & \\
\hline$n$ total & 21 & 0 & 21 & 0 & 240 & 102 & 57 & \\
\hline $\mathrm{n}$ taxa total & 21 & 0 & 21 & 0 & 10 & 6 & 3 & \\
\hline & & & & & & & & \\
\hline & & & & & & & & \\
\hline \multicolumn{9}{|c|}{ Correlation matrix (Spearman): } \\
\hline & & & & & & & & \\
\hline Variables & $\mathrm{n}$ total & taxa total & & & & & & \\
\hline $\mathrm{n}$ total & 1,000 & 0,660 & & & & & & \\
\hline $\mathrm{n}$ taxa & 0,660 & 1,000 & & & & & & \\
\hline \multicolumn{9}{|c|}{ Values in bold are different from 0 with a significance level alpha $=3 E-2$} \\
\hline & & & & & & & & \\
\hline & & & & & & & & \\
\hline \multicolumn{9}{|c|}{ p-values (Spearman): } \\
\hline & & & & & & & & \\
\hline Variables & $\mathrm{n}$ total & n taxa total & & & & & & \\
\hline n total & 3,9502E-06 & $1,5019 E-03$ & & & & & & \\
\hline $\mathrm{n}$ taxa total & $1,5019 \mathrm{E}-03$ & 3,9502E-06 & & & & & & \\
\hline & & & & & & & & \\
\hline & & & & & & & & \\
\hline \multicolumn{9}{|c|}{ Coefficients of determination (Spearman): } \\
\hline & & & & & & & & \\
\hline Variables & $\mathrm{n}$ total & $\mathrm{n}$ taxa total & & & & & & \\
\hline n total & 1,000 & $\overline{0,435}$ & & & & & & \\
\hline $\mathrm{n}$ taxa total & 0,435 & 1,000 & & & & & & \\
\hline
\end{tabular}


4B. Spearman correlation test, $n$ of taxa: dispersed (quad) vs. concentrated charcoal samples

4B1-Quads:

\begin{tabular}{|c|c|c|c|c|c|c|c|}
\hline Variable & Observations & Obs. with missing data & Obs. without missing data & Minimum & Maximum & Mean & Std. deviation \\
\hline n Quad & 8 & 0 & 8 & 0 & 240 & 116 & 70 \\
\hline nr. of taxa & 8 & 0 & 8 & 0 & 9 & 6 & 3 \\
\hline & & & & & & & \\
\hline \multicolumn{8}{|c|}{ Correlation matrix (Spearman): } \\
\hline & & & & & & & \\
\hline Variables & n Quad & nr. of taxa & & & & & \\
\hline n Quad & 1,000 & 0,753 & & & & & \\
\hline nr. of taxa & 0,753 & 1,000 & & & & & \\
\hline \multicolumn{8}{|c|}{ Values in bold are different from 0 with a significance level alpha $=3 E-2$} \\
\hline & & & & & & & \\
\hline \multicolumn{8}{|c|}{ p-values (Spearman): } \\
\hline & & & & & & & \\
\hline Variables & n Quad & nr. of taxa & & & & & \\
\hline n Quad & $4,960 \mathrm{E}-05$ & $\overline{4,583 E-02}$ & & & & & \\
\hline nr. of taxa & 4,583E-02 & $4,960 \mathrm{E}-05$ & & & & & \\
\hline & & & & & & & \\
\hline \multicolumn{8}{|c|}{ Coefficients of determination (Spearman): } \\
\hline & & & & & & & \\
\hline Variables & $\mathrm{n}$ total & nr. of taxa & & & & & \\
\hline n Quad & 1,000 & 0,567 & & & & & \\
\hline nr. of taxa & 0,567 & 1,000 & & & & & \\
\hline
\end{tabular}

Note: Positive but not statistically significant correlation at the alpha significance level 0,025 (but significant at the alpha significance level 0,05). As the effective is the lowest for this category (8), the potency of the test might not be ideal.

4B2-SUs:

Summary statistics (Quantitative data):

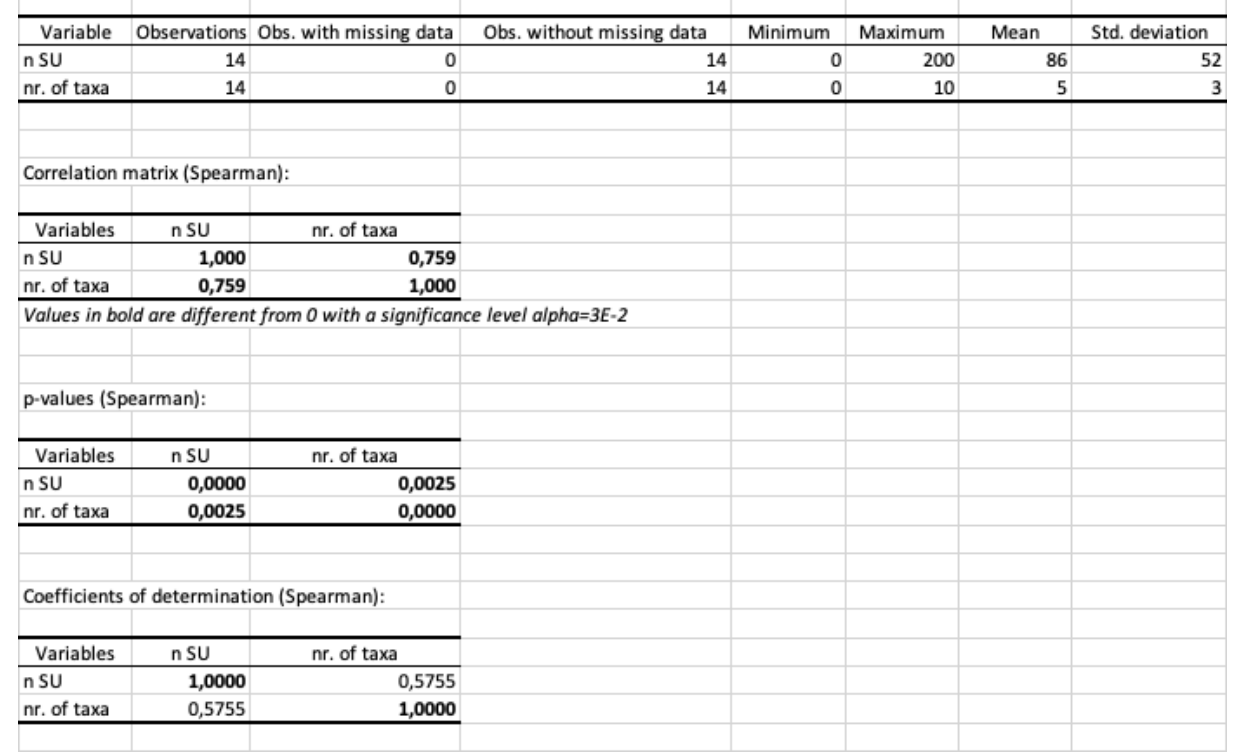


4C. Spearman correlation test, $n$ of taxa: small $([2-4[\mathrm{~mm})$ vs. large $(>4 \mathrm{~mm})$ charcoal fragments

4C1- ]2-4[ mm fragments

Summary statistics (Quantitative data):

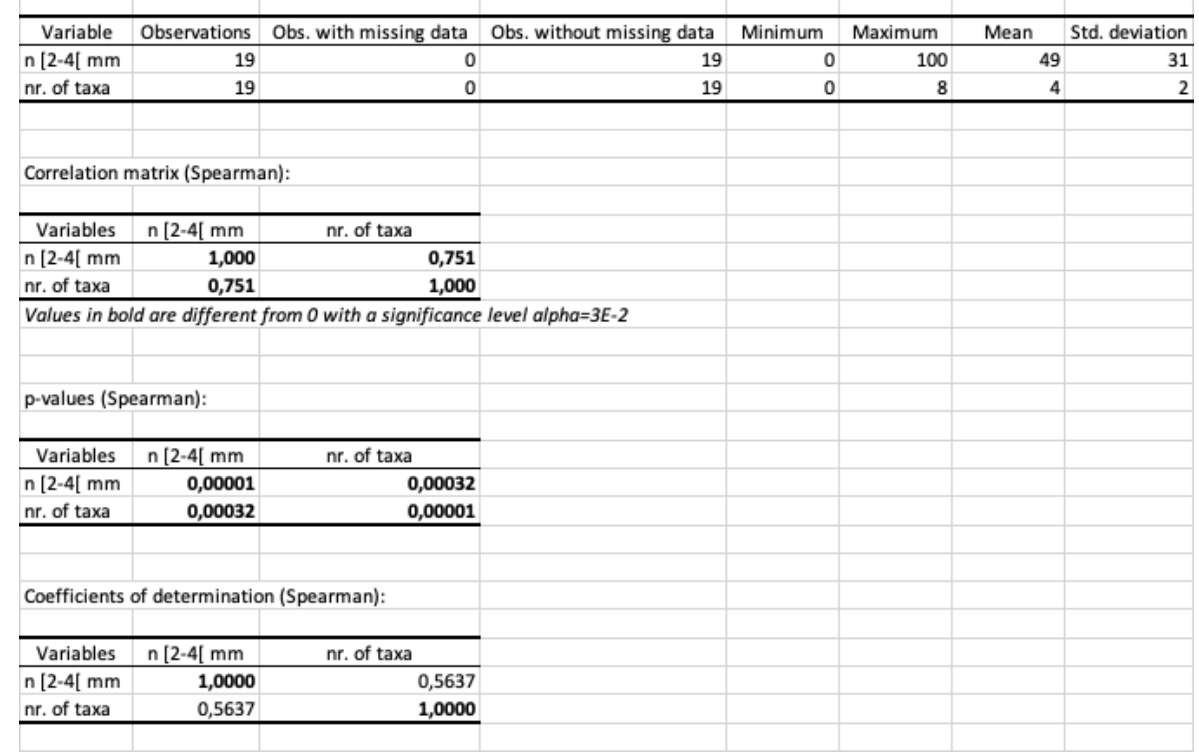

4C2- > $4 \mathrm{~mm}$ fragments

Summary statistics (Quantitative data):

\begin{tabular}{|c|c|c|c|c|c|c|c|}
\hline Variable & Observations & Obs. with missing data & Obs. without missing data & Minimum & Maximum & Mean & Std. deviation \\
\hline$n>4 \mathrm{~mm}$ & 21 & 0 & 21 & 0 & 151 & 57 & 41 \\
\hline nr. of taxa & 21 & 0 & 21 & 0 & 9 & 5 & 2 \\
\hline & & & & & & & \\
\hline \multicolumn{8}{|c|}{ Correlation matrix (Spearman): } \\
\hline & & & & & & & \\
\hline Variables & $n>4 \mathrm{~mm}$ & nr. of taxa & & & & & \\
\hline$n>4 m m$ & 1,000 & 0,682 & & & & & \\
\hline nr. of taxa & 0,682 & 1,000 & & & & & \\
\hline \multicolumn{8}{|c|}{ Values in bold are different from 0 with a significance level alpha $=3 E-2$} \\
\hline & & & & & & & \\
\hline & & & & & & & \\
\hline \multicolumn{8}{|c|}{ p-values (Spearman): } \\
\hline & & & & & & & \\
\hline Variables & $\mathrm{n}>4 \mathrm{~mm}$ & nr. of taxa & & & & & \\
\hline $\mathrm{n}>4 \mathrm{~mm}$ & 3,950E-06 & 9,104E-04 & & & & & \\
\hline nr. of taxa & 9,104E-04 & 3,950E-06 & & & & & \\
\hline & & & & & & & \\
\hline \multicolumn{8}{|c|}{ Coefficients of determination (Spearman): } \\
\hline & & & & & & & \\
\hline Variables & $\mathrm{n}>4 \mathrm{~mm}$ & nr. of taxa & & & & & \\
\hline $\mathrm{n}>4 \mathrm{~mm}$ & 1,000 & 0,465 & & & & & \\
\hline nr. of taxa & 0,465 & 1,000 & & & & & \\
\hline
\end{tabular}




\section{Supplementary Material 5. Non-parametric tests: impact of charcoal fragment size and sample type on number of identified taxa.}

\section{A. Number of taxa identified within each type of sample (SU vs. Quad)}

\section{Objectives:}

It is generally assumed that charcoal concentrations (here: label "SU") are floristically less diverse than dispersed charcoal samples (here: label "quad"). We want to test if the distribution of observed values (here: nr. of taxa) is equivalent within samples coming from SUs or from Quads. For this, we assume independence between quads and SUs and perform a Mann-Whitney test, adapted to small samples. Significance level alpha chosen for the test: 0,025 .

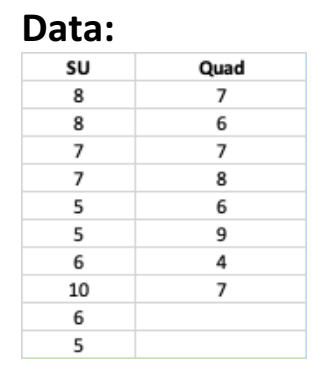

Note: low taxa frequencies $(1 ; 2)$ have been removed

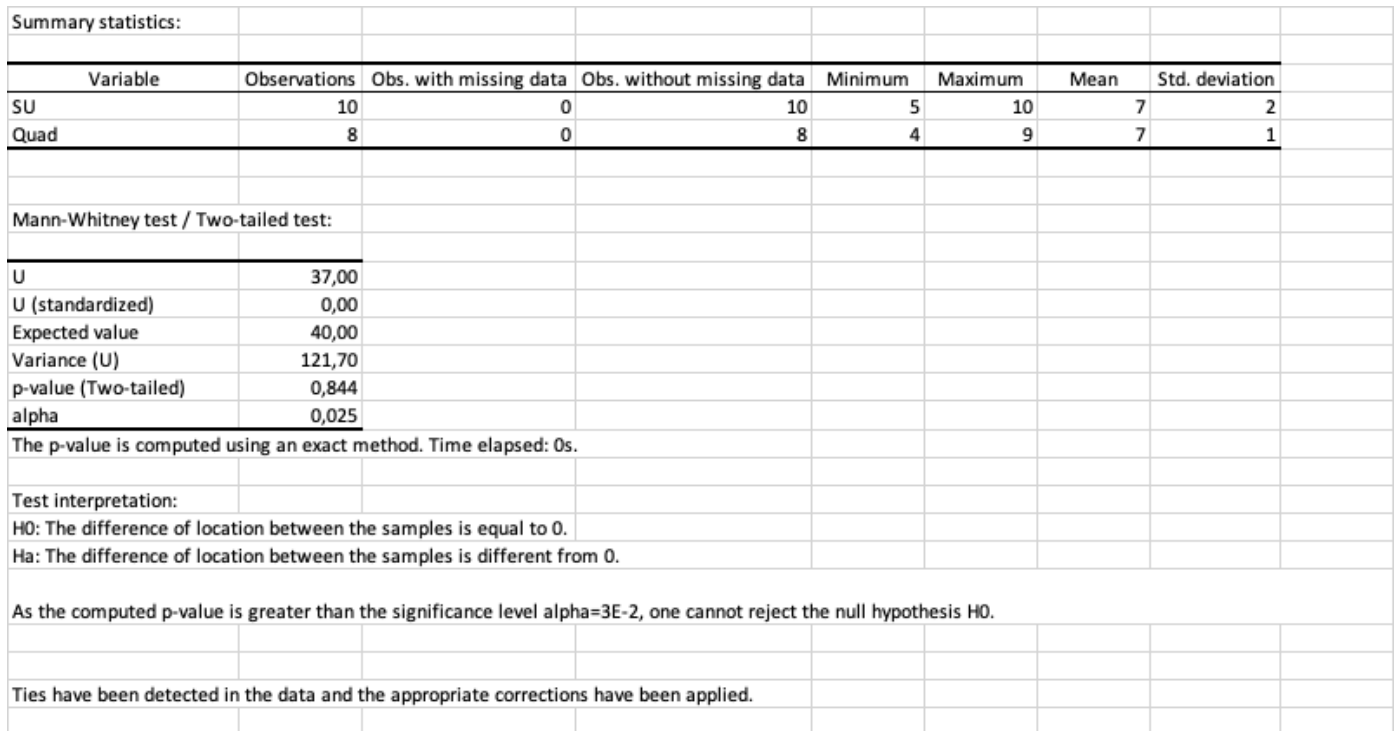

\section{Interpretation:}

No significant difference was detected in the distributions of the number of taxa present in the dispersed and the concentrated charcoal samples. 


\section{B. Number of taxa per size class $([2-4[\mathrm{~mm}$ and $>4 \mathrm{~mm})$}

\section{Objectives:}

Several studies have shown that the study of different size classes does not have a significant impact on taxonomic richness. We want to test if the distribution of observed values (here: nr. of taxa) is equivalent within two populations, large (>4 mm) vs. smaller ([2-4[ mm) charcoal fragments. For this, we assume independence between the two size classes and perform a Mann-Whitney test, adapted to small samples. Significance level alpha chosen for the test: 0,025 .

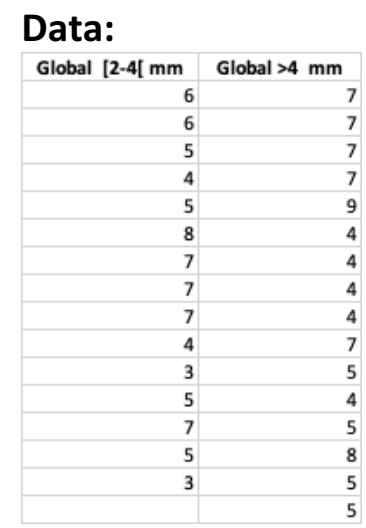

Note: low taxa frequencies $(1 ; 2)$ have been removed

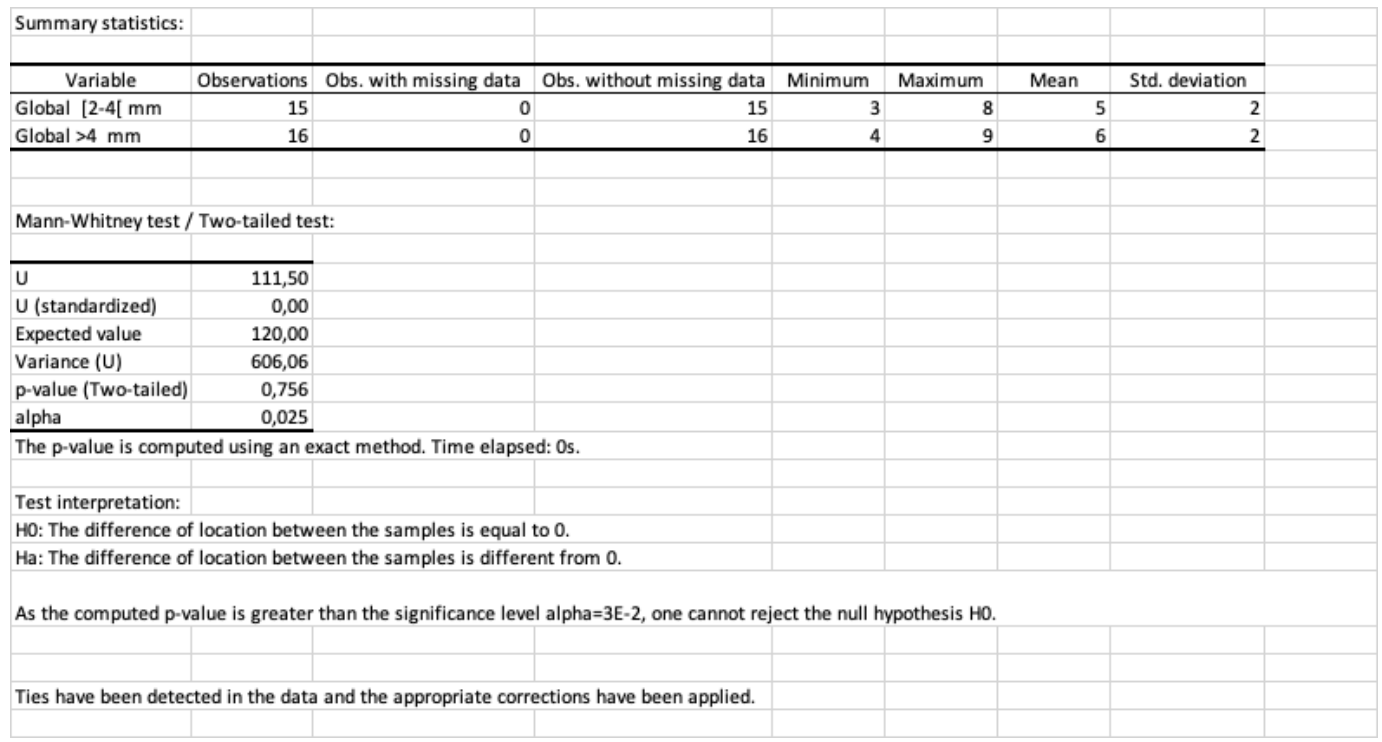

\section{Interpretation:}

No significant difference was detected in the distributions of the number of taxa present in the larger and the smaller size classes. 


\section{C. Number of taxa within each sample type (SU, Quad) and size class ([2-4[ $\mathrm{mm}$ and $>4 \mathrm{~mm})$}

\section{Objectives:}

We want to analyse the previous data more in-depth by taking into account both parameters, type of sample and size class. As each individual (charcoal fragment) composing the samples is allocated to only one size class and sample type, we can assume independence between our four variables. We want to test if the distribution of observed values (here: $\mathrm{nr}$. of taxa) is equivalent within four variables, large (>4 mm) scattered and concentrated charcoal vs. smaller ([2-4[ $\mathbf{~ m m})$ scattered and concentrated charcoal fragments. For this, we ran a Kruskal-Wallis and multiple comparisons (Dunn's procedure) tests, adapted to small samples. Significance level alpha chosen for the test: 0,025.

\section{Data:}

\begin{tabular}{|c|c|c|c|}
\hline Quad [2-4[ mm & Quad $>4 \mathrm{~mm}$ & SU $[2-4[\mathrm{~mm}$ & $S U>4 \mathrm{~mm}$ \\
\hline 6 & 7 & 7 & 4 \\
\hline 6 & 7 & 7 & 4 \\
\hline 5 & 7 & 7 & 4 \\
\hline 4 & 7 & 4 & 7 \\
\hline 5 & 9 & 3 & 5 \\
\hline \multirow[t]{5}{*}{8} & 4 & 5 & 4 \\
\hline & & 7 & 5 \\
\hline & & 5 & 8 \\
\hline & & 3 & 5 \\
\hline & & & 5 \\
\hline
\end{tabular}

Note: low taxa frequencies $(1 ; 2)$ have been removed

\begin{tabular}{|c|c|c|c|c|c|c|c|}
\hline \multicolumn{8}{|l|}{ Summary statistics: } \\
\hline Variable & Observations & Obs. with missing data & Obs. without missing data & Minimum & Maximum & Mean & Std. deviation \\
\hline Quad $[2-4[\mathrm{~mm}$ & 10 & 4 & 6 & 4 & 8 & 5,7 & 1,4 \\
\hline Quad $>4 \mathrm{~mm}$ & 10 & 4 & 6 & 4 & 9 & 6,8 & 1,6 \\
\hline SU $[2-4[\mathrm{~mm}$ & 10 & 1 & 9 & 3 & 7 & 5,3 & 1,7 \\
\hline $\mathrm{SU}>4 \mathrm{~mm}$ & 10 & 0 & 10 & 4 & 8 & 5,1 & 1,4 \\
\hline & & & & & & & \\
\hline \multicolumn{8}{|c|}{ Kruskal-Wallis test / Two-tailed test: } \\
\hline & & & & & & & \\
\hline K (Observed value) & 4,183 & & & & & & \\
\hline $\mathrm{K}$ (Critical value) & 9,348 & & & & & & \\
\hline DF & 3,000 & & & & & & \\
\hline p-value (one-tailed) & 0,242 & & & & & & \\
\hline alpha & 0,025 & & & & & & \\
\hline \multicolumn{8}{|c|}{ An approximation has been used to compute the p-value. } \\
\hline & & & & & & & \\
\hline \multirow{2}{*}{\multicolumn{8}{|c|}{$\begin{array}{l}\text { Test interpretation: } \\
\text { HO: The samples come from the same population. }\end{array}$}} \\
\hline & & & & & & & \\
\hline \multicolumn{8}{|c|}{ Ha: The samples do not come from the same population. } \\
\hline \multicolumn{8}{|c|}{ As the computed p-value is greater than the significance level alpha=3E-2, one cannot reject the null hypothesis $\mathrm{H} 0$. } \\
\hline Ties have been dete & in the data and th & he appropriate correction & s have been applied. & & & & \\
\hline
\end{tabular}

Interpretation:

No significant difference was detected in the distributions of at least one pair of variables. 
Multiple pairwise comparisons using Dunn's procedure / Two-tailed test:

\begin{tabular}{|c|c|c|c|c|}
\hline Sample & Frequency & Sum of ranks & Mean of ranks & Groups \\
\hline Quad $>4 \mathrm{~mm}$ & 6 & 133,000 & 22,167 & A \\
\hline Quad [2-4[ mm & 6 & 99,500 & 16,583 & A \\
\hline SU $[2-4[\mathrm{~mm}$ & 9 & 132,000 & 14,667 & A \\
\hline $\mathrm{SU}>4 \mathrm{~mm}$ & 10 & 131,500 & 13,150 & A \\
\hline & & & & \\
\hline \multicolumn{5}{|c|}{ Pairwise comparisons: } \\
\hline \multirow{2}{*}{\multicolumn{5}{|c|}{ Differences: }} \\
\hline & & & & \\
\hline & Quad [2-4[ mm & Quad >4 mm & SU $[2-4[\mathrm{~mm}$ & $\mathrm{SU}>4 \mathrm{~mm}$ \\
\hline Quad [2-4[ mm & 0,000 & $-5,583$ & 1,917 & 3,433 \\
\hline Quad >4 mm & 5,583 & 0,000 & 7,500 & 9,017 \\
\hline SU [2-4[ mm & $-1,917$ & $-7,500$ & 0,000 & 1,517 \\
\hline $\mathrm{SU}>4 \mathrm{~mm}$ & $-3,433$ & $-9,017$ & $-1,517$ & 0,000 \\
\hline & & & & \\
\hline \multicolumn{5}{|l|}{ p-values: } \\
\hline & Quad $[2-4[\mathrm{~mm}$ & Quad $>4 \mathrm{~mm}$ & SU $[2-4[\mathrm{~mm}$ & $\mathrm{SU}>4 \mathrm{~mm}$ \\
\hline Quad [2-4[ mm & 1,000 & 0,274 & 0,681 & 0,452 \\
\hline Quad $>4 \mathrm{~mm}$ & 0,274 & 1,000 & 0,108 & 0,048 \\
\hline SU $[2-4[\mathrm{~mm}$ & 0,681 & 0,108 & 1,000 & 0,709 \\
\hline $\mathrm{SU}>4 \mathrm{~mm}$ & 0,452 & 0,048 & 0,709 & 1,000 \\
\hline \multicolumn{5}{|c|}{ Significant differences: } \\
\hline & & & & \\
\hline & Quad [2-4[ mm & Quad $>4 \mathrm{~mm}$ & SU $[2-4[\mathrm{~mm}$ & $\mathrm{SU}>4 \mathrm{~mm}$ \\
\hline Quad [2-4[ mm & No & No & No & No \\
\hline Quad >4 mm & No & No & No & No \\
\hline SU $[2-4[\mathrm{~mm}$ & No & No & No & No \\
\hline $\mathrm{SU}>4 \mathrm{~mm}$ & No & No & No & No \\
\hline
\end{tabular}

Note: even though the differences are not significant at the alpha level of 0.025, the most differing pair corresponds to the distribution of the number of taxa within the Quads and the SUs of the larger charcoal size class (p-value: 0.048). However, as the number of comparisons increase and the effective decrease, the potency of the test also decreases. 


\section{Supplementary Material 6- Non parametric tests. Impact of charcoal fragment size and sample type on the abundance of Quercus}

\section{A. Oak frequencies: impact of type of sample (Quad vs. SU) Objectives:}

It is generally assumed that charcoal concentrations (here: label "SU") yield aberrant proportions between taxa, contrarily to dispersed charcoal samples (here: label "quad"). We want to test if the distribution of observed values (here: Quercus abundance) is equivalent within samples coming from SUs or from Quads. For this, we assume independence between quads and SUs and perform a Mann-Whitney test, adapted to the comparison of ordinal qualitative samples. We thus categorized our percentages into ordinal values that make sense from an anthracological point of view. For instance, in Chabal's fragmentation studies, the point up to which a difference is significant is considered to be superior to $10 \%$ (Chabal 1997). We only partially agree, as at the level of the anthracological spectrum a $10 \%$ variation seems less significant when the frequencies are high (superior to 50\%), but can be determining when they are low (below 20\%). We thus created the following categories:

\begin{tabular}{|l|l|l|}
\hline Percentage & Abundance & Class \\
\hline 0 & absent & 0 \\
\hline up to $5 \%$ & low & 1 \\
\hline up to $15 \%$ & secondary & 2 \\
\hline less than 30\% & fairly abundant & 3 \\
\hline $30 \%$ and higher & abundant & 4 \\
\hline
\end{tabular}

Dataset:

\begin{tabular}{|r|r|}
\hline $\begin{array}{r}\text { Quad } \% \\
\text { Quercus }\end{array}$ & $\begin{array}{c}\text { SU \% } \\
\text { Quercus }\end{array}$ \\
\hline 2 & 2 \\
\hline 2 & 2 \\
\hline 3 & 2 \\
\hline 2 & 2 \\
\hline 2 & 1 \\
\hline 3 & 4 \\
\hline 2 & 2 \\
\hline 1 & 2 \\
\hline & 2 \\
\hline & 2 \\
\hline
\end{tabular}

Significance level alpha chosen for the test: 0.025

Note: the assumption of independence of the variables "quad" and "SU" is effective, as the categories "sample type" can be considered as coming from two different populations for statistical purposes (no fragment is counted twice). On the contrary, inter-comparisons between sample types and fragment sizes are here less pertinent, as each category includes a proportion of fragments from the other. Thus the distribution of values according to fragment size is treated in a separate Mann-Whitney test below (see 6.B.)

\section{Interpretation:}

No significant differences were detected in the distributions of Quercus values -the values of quads and SUs follow comparable distributions. 


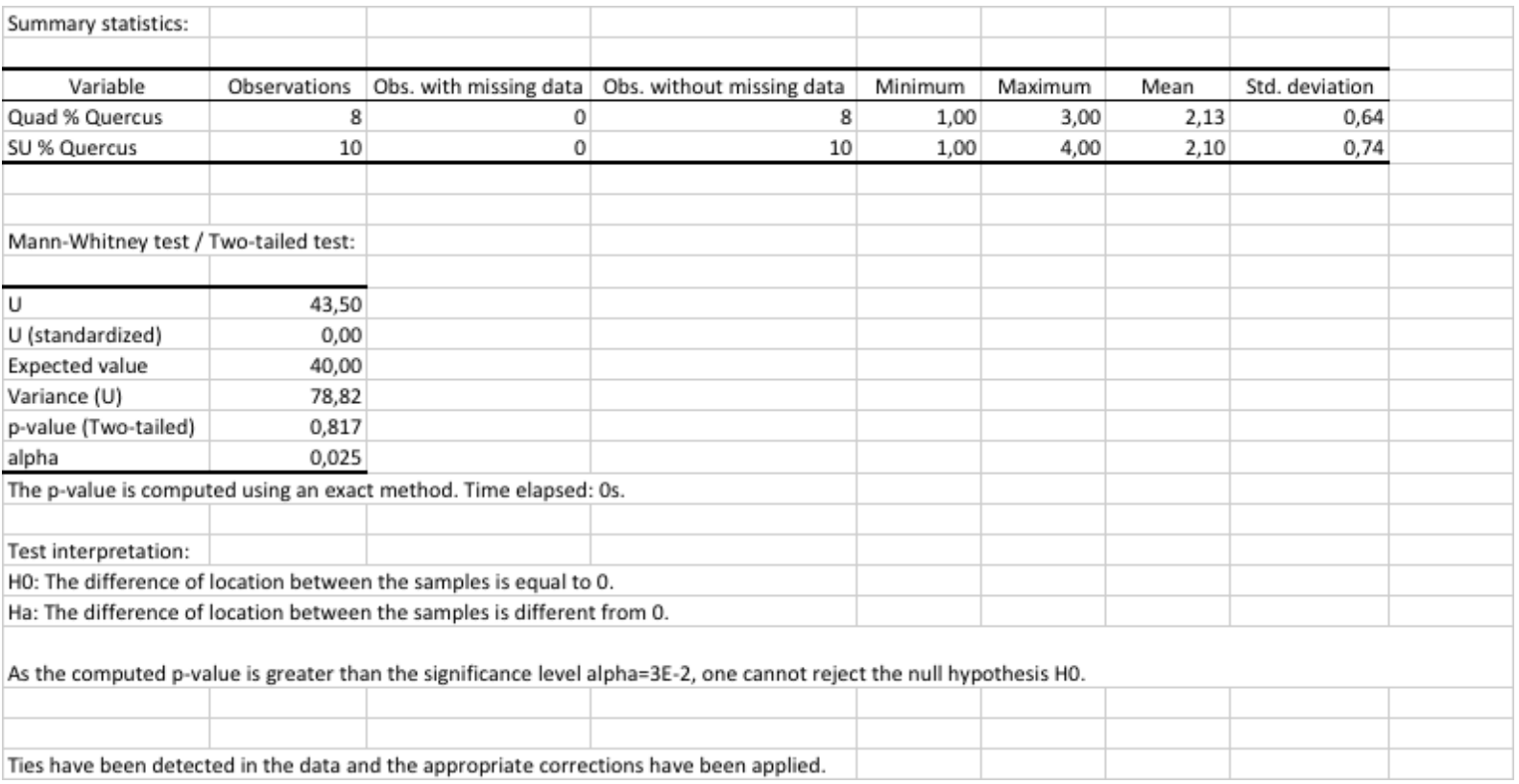

\section{B. Oak frequencies: impact of size class (Global [2-4[ $\mathrm{mm}$ vs. Global >4 mm)}

\section{Objectives:}

It is assumed that the study of different size fractions is not thought to influence significantly taxa percentages. We want to test if the distribution of observed values (here: Quercus abundance) is equivalent within samples coming from different size categories (]2-4[ $\mathrm{mm}->4$ $\mathrm{mm}$ ). For this, we assume independence between these two classes and perform a MannWhitney test, adapted to the comparison of ordinal qualitative samples, on our ordinal Quercus values.

Dataset:

\begin{tabular}{|r|r|}
\hline [2-4[ mm -Quercus $\%$ & $\begin{array}{c}>\text { mm Quercus } \\
\%\end{array}$ \\
\hline 2 & 2 \\
\hline 2 & 3 \\
\hline 2 & 1 \\
\hline 3 & 2 \\
\hline 3 & 2 \\
\hline 2 & 1 \\
\hline 2 & 0 \\
\hline 2 & 1 \\
\hline 2 & 2 \\
\hline 2 & 2 \\
\hline 4 & 1 \\
\hline 2 & 2 \\
\hline 2 & 1 \\
\hline 3 & 2 \\
\hline 2 & 1 \\
\hline & 2 \\
\hline
\end{tabular}




\begin{tabular}{|c|c|c|c|c|c|c|c|}
\hline Variable & Observations & Obs. with missing data & Obs. without missing data & Minimum & Maximum & Mean & Std. deviation \\
\hline [2-4[ $\mathrm{mm}$-Quercus \% & 15 & 0 & 15 & 2 & 4 & 2,33 & 0,62 \\
\hline$>4 \mathrm{~mm}$ Quercus \% & 16 & 0 & 16 & 0 & 3 & 1,56 & 0,73 \\
\hline & & & & & & & \\
\hline \multicolumn{8}{|c|}{ Mann-Whitney test / Two-tailed test: } \\
\hline & & & & & & & \\
\hline $\bar{U}$ & 183,50 & & & & & & \\
\hline$U$ (standardized) & 0,00 & & & & & & \\
\hline Expected value & 120,00 & & & & & & \\
\hline Variance (U) & 487,10 & & & & & & \\
\hline p-value (Two-tailed) & $<0,0001$ & & & & & & \\
\hline alpha & 0,025 & & & & & & \\
\hline \multicolumn{8}{|c|}{ The p-value is computed using an exact method. Time elapsed: 0 s. } \\
\hline & & & & & & & \\
\hline \multirow{2}{*}{\multicolumn{8}{|c|}{ HO: The difference of location between the samples is equal to 0 . }} \\
\hline & & & & & & & \\
\hline \multicolumn{8}{|c|}{ Ha: The difference of location between the samples is different from 0 . } \\
\hline \multicolumn{8}{|c|}{ As the computed p-value is lower than the significance level alpha= $3 \mathrm{E}-2$, one should reject the null hypothesis $\mathrm{HO}$, and accept the alternative hypothesis $\mathrm{Ha}$. } \\
\hline & & & & & & & \\
\hline & & & & & & & \\
\hline \multicolumn{8}{|c|}{ Ties have been detected in the data and the appropriate corrections have been applied. } \\
\hline & & & & & & & \\
\hline
\end{tabular}

\section{Interpretation:}

Significant differences were detected in the distributions of the values- the smaller size class does not yield the same Quercus values as the larger one.

\section{C. Oak frequencies within each sample type (SU vs. Quad) vs. size class ([2-4[ $\mathrm{mm}$ vs. $>4 \mathrm{~mm}$ )}

\section{Objectives:}

We want to analyze the previous data more in-depth by taking into account both parameters, type of sample and size class. As each individual (charcoal fragment) composing the samples is allocated to only one size class and sample type, we can assume independence between our variables. We want to test if the distribution of observed values (here: oak abundance) is equivalent within four variables, large scattered (Quad $>4 \mathrm{~mm}$ ) and concentrated ( $\mathrm{SU}>4 \mathrm{~mm}$ ) charcoal vs. smaller scattered (Quad $[2-4[\mathrm{~mm}$ ) and concentrated (SU $[2-4[\mathrm{~mm}$ ) charcoal fragments. For this, we ran a Kruskal-Wallis and multiple comparisons (Dunn's procedure) tests, adapted to small samples. Significance level alpha chosen for the test: 0.025 .

Dataset:

\begin{tabular}{|r|r|r|r|}
\hline $\begin{array}{r}\text { SU [2-4[ } \\
\mathbf{~ m m}\end{array}$ & SU $>\mathbf{4 ~} \mathbf{~ m m}$ & $\begin{array}{c}\text { Quad [2-4[ } \\
\mathbf{m m}\end{array}$ & $\begin{array}{c}\text { Quad }>\mathbf{4} \\
\mathbf{m m}\end{array}$ \\
\hline 2 & 0 & 2 & 2 \\
\hline 2 & 1 & 2 & 3 \\
\hline 2 & 2 & 2 & 1 \\
\hline 2 & 2 & 3 & 1 \\
\hline 4 & 1 & 3 & 2 \\
\hline 2 & 2 & 2 & 1 \\
\hline 2 & 1 & & \\
\hline 3 & 2 & & \\
\hline 2 & 1 & & \\
\hline & 2 & & \\
\hline
\end{tabular}

Note: as the samples are reassigned within sample and size classes, the effectives and thus, the potency of the test, decrease. 
Summary statistics:

\begin{tabular}{|l|r|r|r|r|r|r|r|}
\hline \multicolumn{1}{|c|}{ Variable } & Observations & Obs. with missing data & Obs. without missing data & Minimum & Maximum & Mean & Std. deviation \\
\hline SU $[2-4[\mathrm{~mm}$ & 10 & 1 & 9 & 2 & 4 & 2,33 \\
\hline SU $>4 \mathrm{~mm}$ & 10 & 0 & 10 & 0 & 2 & 1,70 & 0,71 \\
\hline Quad $[2-4[\mathrm{~mm}$ & 10 & 4 & 6 & 2 & 3 & 2,33 & 0,52 \\
\hline Quad $>4 \mathrm{~mm}$ & 10 & 4 & 6 & 1 & 3 & 1,67 & 0,82 \\
\hline
\end{tabular}

Kruskal-Wallis test / Two-tailed test:

\begin{tabular}{|l|r|}
\hline K (Observed value) & 9,736 \\
\hline K (Critical value) & 9,348 \\
\hline DF & 3,000 \\
\hline p-value (one-tailed) & 0,021 \\
\hline alpha & 0,025 \\
\hline
\end{tabular}

alpha $\quad 0,025$

An approximation has been used to compute the $p$-value.

Test interpretation:

HO: The samples come from the same population.

Ha: The samples do not come from the same population.

As the computed p-value is lower than the significance level alpha=3E-2, one should reject the null hypothesis $\mathrm{HO}$, and accept the alternative hypothesis $\mathrm{Ha}$

Ties have been detected in the data and the appropriate corrections have been applied.

Kruskal-Wallis test interpretation:

At least one pair of values shows highly significant differences.

Multiple pairwise comparisons using Dunn's procedure / Two-tailed test:

\begin{tabular}{|c|c|c|c|c|c|}
\hline Sample & Frequency & Sum of ranks & Mean of ranks & \multicolumn{2}{|c|}{ Groups } \\
\hline Quad [2 A[ $\mathrm{mm}$ & 6 & 127,000 & 21.157 & A & \\
\hline SU $[2-4[\mathrm{~mm}$ & 9 & 182,000 & 20,222 & A & \\
\hline Quad $>4 \mathrm{~mm}$ & 6 & 78,500 & 13,083 & A & $\mathrm{B}$ \\
\hline $\mathrm{SU}>4 \mathrm{~mm}$ & 10 & 108,500 & 10,850 & 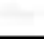 & $\mathrm{B}$ \\
\hline
\end{tabular}

Pairwise comparisons:

Differences:

\begin{tabular}{|c|c|c|c|c|}
\hline & $\mathrm{su}[2-4[\mathrm{~mm}$ & $\mathrm{SU}>4 \mathrm{~mm}$ & Quad $[2-4[\mathrm{~mm}$ & Quad > $4 \mathrm{~mm}$ \\
\hline $5 U[2-4 \mid \mathrm{mm}$ & 0,0000 & 9,3722 & $-0,9444$ & 7,1389 \\
\hline $\mathrm{SU}>4 \mathrm{~mm}$ & $-9,3722$ & 0,0000 & $-10,3167$ & $-2,2333$ \\
\hline Quad [2-4] $\mathrm{mm}$ & 0,9444 & 10,3167 & 0,0000 & 8,0833 \\
\hline Quad $>4 \mathrm{~mm}$ & $-7,1389$ & 2,2333 & $-8,0833$ & 0,00000 \\
\hline
\end{tabular}

p-values:

\begin{tabular}{lrrrrr}
\hline & SU $[2-4] \mathrm{mm}$ & SU $>4 \mathrm{~mm}$ & Quad [2-4[mm & Quad $>4 \mathrm{~mm}$ \\
\hline SU $[2-4[\mathrm{~mm}$ & 1,0000 & 0,0117 & 0,8247 & 0,0940 \\
SU $>4 \mathrm{~mm}$ & 0,0117 & 1,0000 & 0,0135 & 0,5928 \\
Quad $[24[\mathrm{~mm}$ & 0,8247 & 0,0135 & 1,0000 & 0,0834 \\
Quad $>4 \mathrm{~mm}$ & 0,0940 & 0,5928 & 0,0834 & 1,00000 \\
\hline
\end{tabular}

Significant differences:

\begin{tabular}{lcccc}
\hline & SU $[2.4[\mathrm{~mm}$ & SU $>4 \mathrm{~mm}$ & Quad $[2-4[\mathrm{~mm}$ & Quad $>4 \mathrm{~mm}$ \\
\hline SU $[2-4] \mathrm{mm}$ & No & Yes & No & No \\
SU $>4 \mathrm{~mm}$ & Yes & No & Yes & No \\
Quad $[2-4] \mathrm{mm}$ & No & Yes & No & No \\
Quad $>4 \mathrm{~mm}$ & No & No & No & No \\
\hline
\end{tabular}

